\title{
Stroke Statistics in Korea: Part I. Epidemiology and Risk Factors: A Report from the Korean Stroke Society and Clinical Research Center for Stroke
}

\author{
Keun-Sik Hong, , Oh Young Bang, ${ }^{\mathrm{b}}$ Dong-Wha Kang, ${ }^{\mathrm{c}}$ Kyung-Ho Yu, ${ }^{\mathrm{d}}$ Hee-Joon Bae, ${ }^{\mathrm{e}}$ Jin Soo Lee, ${ }^{\mathrm{f}}$ \\ Ji Hoe Heo, ${ }^{\mathrm{g}}$ Sun U. Kwon, ${ }^{\mathrm{c}}$ Chang Wan Oh, ${ }^{\mathrm{h}}$ Byung-Chul Lee, ${ }^{\mathrm{d}}$ Jong S. Kim, ${ }^{\mathrm{c}}$ Byung-Woo Yoon ${ }^{\mathrm{e}}$ \\ ${ }^{a}$ Department of Neurology, Ilsan Paik Hospital, Inje University College of Medicine, Goyang; \\ ${ }^{b}$ Department of Neurology, Samsung Medical Center, Sungkyunkwan University School of Medicine, Seoul; \\ 'Department of Neurology, University of Ulsan College of Medicine, Seoul; \\ ${ }^{\mathrm{d} D}$ Department of Neurology, Hallym University College of Medicine, Anyang; \\ eDepartment of Neurology, Seoul National University College of Medicine, Seoul; \\ ${ }^{\mathrm{f}}$ Department of Neurology, Ajou University School of Medicine, Suwon; \\ ${ }^{g}$ Department of Neurology, Yonsei University College of Medicine, Seoul; \\ ${ }^{\mathrm{h}}$ Department of Neurosurgery, Seoul National University College of Medicine, Seoul, Korea
}

The aim of the Part I of Stroke Statistics in Korea is to summarize nationally representative data of the epidemiology and risk factors of stroke in a single document. Every year, approximately 105,000 people experience a new or recurrent stroke and more than 26,000 die of stroke, which indicates that every 5 minutes stroke attacks someone and every 20 minutes stroke kills someone in Korea. Stroke accounts for roughly 1 of every 10 deaths. The estimated stroke prevalence is about 795,000 in people aged $\geq 30$ years. The nationwide total cost for stroke care was 3,737 billion Korean won (US $\$ 3.3$ billion) in 2005. Fortunately, the annual stroke mortality rate decreased substantially by $28.3 \%$ during the first decade of the 21 th century (53.2/100,000 in 2010). Among OECD countries, Korea had the lowest in-hospital 30-day case-fatality rate for ischemic stroke and ranked third lowest for hemorrhagic stroke in 2009. The proportion of ischemic stroke has steadily increased and accounted for $76 \%$ of all strokes in 2009. According to hospital registry studies, the 90-day mortality rate was 3-7\% for ischemic stroke and 17\% for intracerebral hemorrhage. For risk factors, among Korean adults $\geq 30$ years of age, one in 3-4 has hypertension, one in 10 diabetes, and one in 7 hypercholesterolemia. One in 3 Korean adults $\geq 19$ years of age is obese. Over the last 10 years, the prevalence of hypertension slightly decreased, but the prevalence of diabetes, hypercholesterolemia, and obesity increased. Smoking prevalence in men has decreased, but is still as high as $48 \%$. This report could be a valuable resource for establishing health care policy and guiding future research directions.

Keywords Stroke; Statistics; Epidemiology; Risk factor
Correspondence: Byung-Woo Yoon Department of Neurology, Seoul National University Hospital, 101 Daehak-ro, Jongno-gu, Seoul 110-744, Korea

Tel: +82-2-2072-2875

Fax: +82-2-3672-7553

E-mail: bwyoon@snu.ac.kr

Received: September 28, 2012

Revised: December 27, 2012

Accepted: December 27, 2012

This work was supported by the grant (A102065) of the Korea Health REtD project, Ministry of Health and Welfare, Republic of Korea (K.-S.H., K.-H.Y., H.-J.B., J.-H.H., B.-C.L., B.-W.Y.).

The authors have no financial conflicts of interest.
Stroke is a major health burden in Korea as well as worldwide. Since the population in Korea is aging fastest among the Organization for Economic Cooperation and Development
(OECD) countries, ${ }^{1}$ stroke burden must substantially increase in the near future. Korea has achieved great economic growth over the past half-century, and Korea's Gross Domestic Product 
(GDP) ranks 15th in the world in 2011. Stroke research in Korea has also achieved great advances. The annual growth of clinical and epidemiological stroke articles of Korea was more than twice the worldwide average, and for the quantity of articles Korea was ranked on the 8 th position worldwide, 2 nd position after Japan among Asian countries. ${ }^{2}$ However, despite these achievements, a representative summary of stroke statistics in Korea has not been formally published. As a result, establishing an efficient health care plan and guiding future research directions to reduce the burden of stroke in Korea lack firm scientific underpinning. Accordingly, the Korean Stroke Society (http:// www.stroke.or.kr/) and the Clinical Research Center for Stroke (http://www.stroke-crc.or.kr/) decided to summarize nationally representative data on stroke and to present them in a single document of Stroke Statistics in Korea. The current report focuses on stroke epidemiology and risk factors, and data of acute stroke management will be presented in another future report. For the current report, we searched the most representative national data from reports of the Korean government or related organizations and published articles. When representative national data are not available, we present the most relevant data of hospital-based studies from a literature review, recognizing the limitations. If there are discrepancies in data across reports, we adopt data of original reports rather than summary reports. The current report of Stroke Statistics in Korea would be a valuable resource for healthcare providers, researchers, policy makers, and the public who seek the best national data on stroke.

\section{Stroke incidence}

Each year, about 105,000 Korean people experience a new or recurrent stroke. On average, every 5 minutes stroke attacks

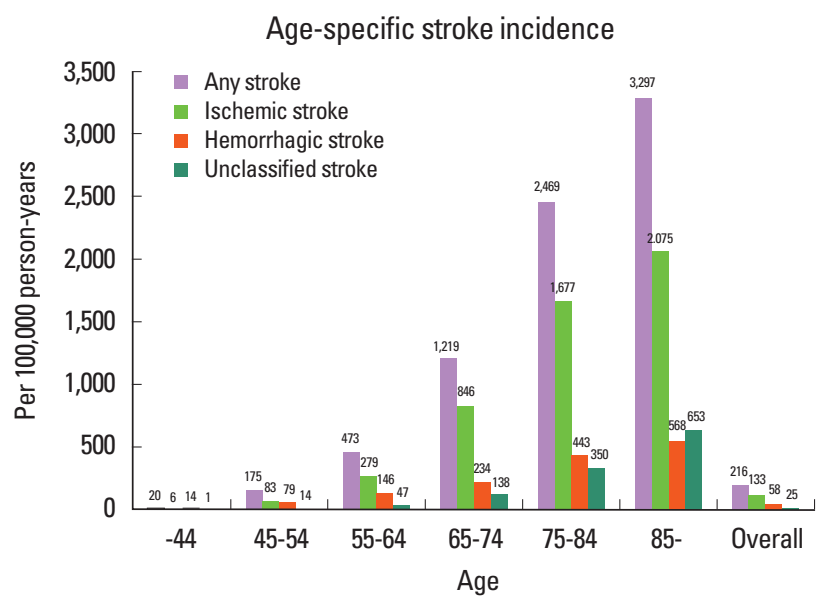

Figure 1. Age-specific stroke incidence. Source: Korean Center for Disease Control. Construction of National Surveillance System for Cardiovascular \& Cerebrovascular Diseases 2006. someone in Korea. The stroke incidence was adopted from the 2006 report of the Construction of National Surveillance System for Cardiovascular and Cerebrovascular Diseases, which analyzed the 2004 in-surance claim database of the Korean Health Insurance Review Agency and national death certificate data to estimate the nationwide stroke incidence in Korea. ${ }^{3}$ In that study, the stroke diagnosis of the insurance claim data was certified from the review of individual cases for a representative sample, using a diagnostic algorithm combining clinical and imaging data. According to a nation-wide hospital-based stroke registry study, one in five ischemic strokes or TIAs was a recurrent stroke. ${ }^{4}$

The estimated incidence is 216 per 100,000 person-years. The age-specific stroke incidence is presented in Figure 1. With increasing age, the incidence per 100,000 person-years steeply increased from 20 in population aged $\leq 44$ years to 3,297 in those aged $\geq 85$ years. The overall incidence was greater in women $(220 / 100,000$ person-years) than in men $(213 / 100,000$ person-years). However, when stratified by age group, the incidence was greater in men than in women across all age groups (Figure 2). The discrepancy is attributed to more elderly population in women than in men. ${ }^{3}$

Stroke in the population aged 65-74 accounted for more than $30 \%$ of all strokes. When stratified by sex, the 65-74 age group accounted for the largest proportion in men, whereas the age group of 75-84 years accounted for the largest proportion in women (Figure 3). For ischemic stroke and unclassified stroke, the relative contribution of each age group was generally consistent with the findings of all strokes (Figures 4 and 5). In contrast, the contribution of younger age groups for hemorrhagic stroke was greater than for ischemic stroke, and hemorrhagic stroke in the population under 55 years of age accounted for

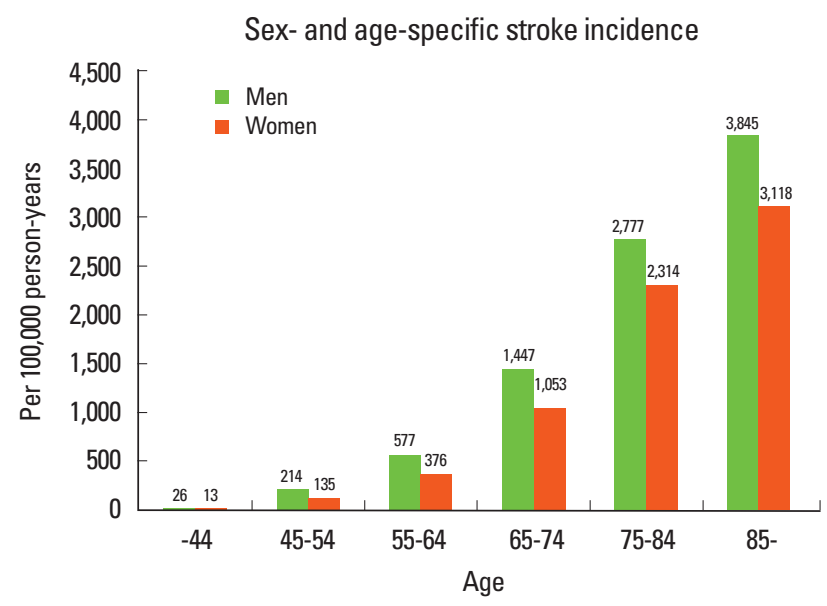

Figure 2. Sex- and age-specific stroke incidence. Source: Korean Center for Disease Control. Construction of National Surveillance System for Cardiovascular \& Cerebrovascular Diseases 2006. 


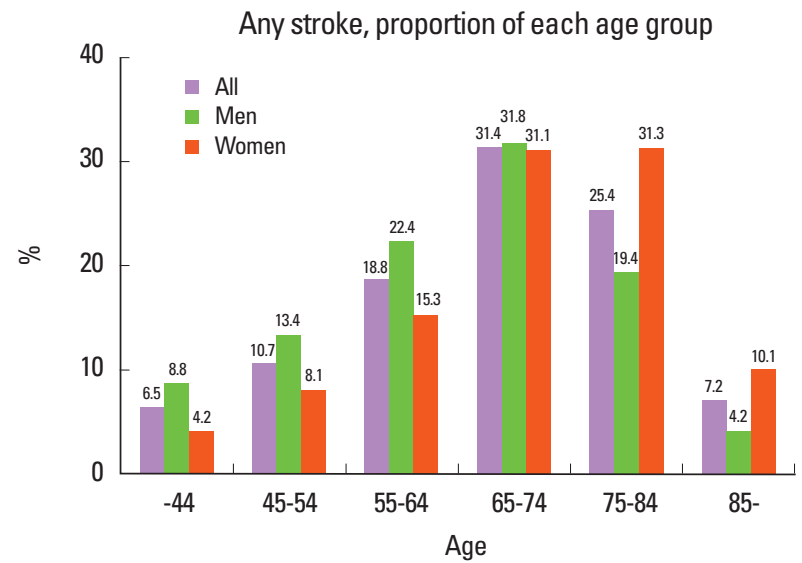

Figure 3. Any stroke, proportion of each age group. Source: Korean Center for Disease Control. Construction of National Surveillance System for Cardiovascular \& Cerebrovascular Diseases 2006.

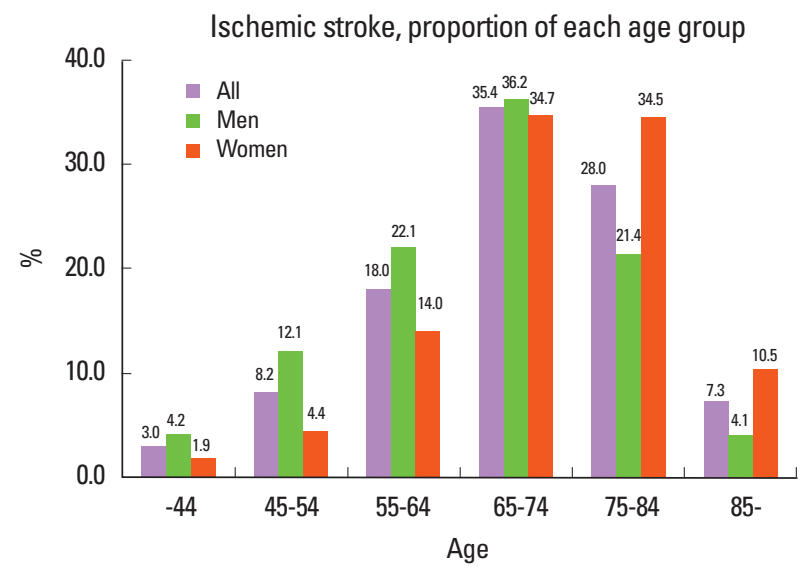

Figure 4. Ischemic stroke, proportion of each age group. Source: Korean Center for Disease Control. Construction of National Surveillance System for Cardiovascular \& Cerebrovascular Diseases 2006.

$41.2 \%$ in men and $27.3 \%$ in women of all hemorrhagic strokes (Figure 6).

By 2030, the annual stroke incidence in Korea is estimated to rise up to 350,000 due to a rapid increase in elderly population. ${ }^{5}$ Stroke incidence data from prospective cohort studies of representative populations are not available in Korea, and future research is needed.

\section{Ischemic stroke and hemorrhagic stroke}

According to an estimation from the database of Korean Health Insurance Review Agency during the period from 1995 to 2003, the age-standardized incidence of ischemic stroke in the population $35-74$ years of age increased annually by $7.18 \%$, whereas hemorrhagic stroke decreased annually by $1.82 \%$ and unclassified stroke by $9.21 \%$. As a result, the proportion of ischemic strokes among all strokes increased from $43 \%$ in 1995 to $65.2 \%$ in 2003 (Figure 7). ${ }^{6}$

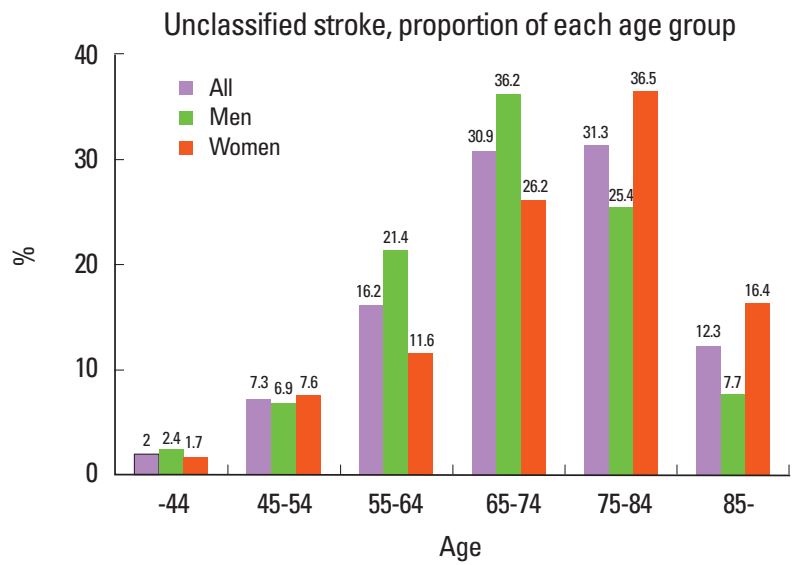

Figure 5. Unclassified stroke, proportion of each age group. Source: Korean Center for Disease Control. Construction of National Surveillance System for Cardiovascular \& Cerebrovascular Diseases 2006.

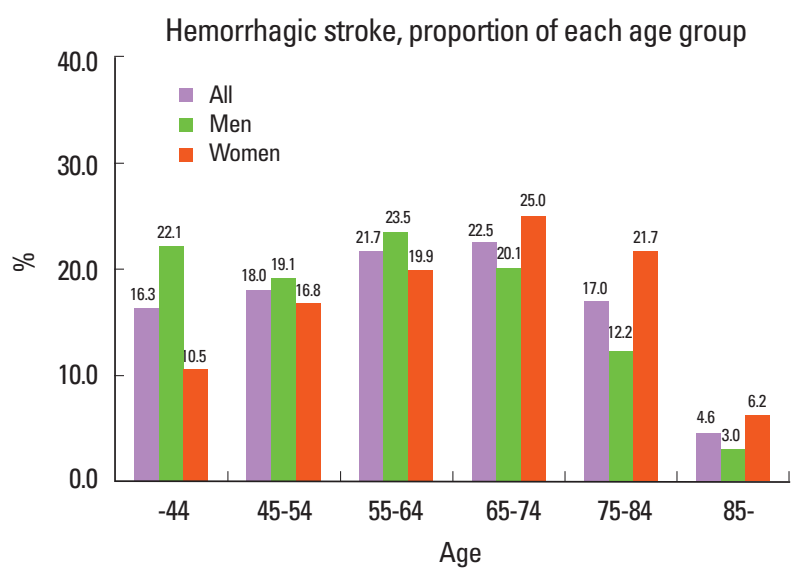

Figure 6. Hemorrhagic stroke, proportion of each age group. Source: Korean Center for Disease Control. Construction of National Surveillance System for Cardiovascular \& Cerebrovascular Diseases 2006.

For stroke admission as a primary diagnostic code (ICD-10 code: hemorrhagic stroke for I60-62, ischemic stroke for I63) during 2001 to 2009, admission for hemorrhagic stroke remained stable, but admission for ischemic stroke increased substantially (Figure 8). Therefore, the proportion of ischemic stroke admissions increased from $64.7 \%$ in 2000 to $76.1 \%$ in 2009 (Figure 9). Among hemorrhagic stroke admissions, the ratio of intracerebral hemorrhage to subarachnoid hemorrhage remained stable, ranging between 2.3 and 2.6..$^{7-10}$

\section{Ischemic stroke subtype}

Data of ischemic stroke subtype from population-based studies are not available. According to a nationwide hospital-based stroke registry study which evaluated the Trial of ORG 10172 in Acute Stroke Treatment (TOAST) classification ${ }^{11}$ for 36,191 ischemic strokes between 2002 and 2010, large artery atherosclerosis (LAA, 36.1\%) was the most common type, followed 


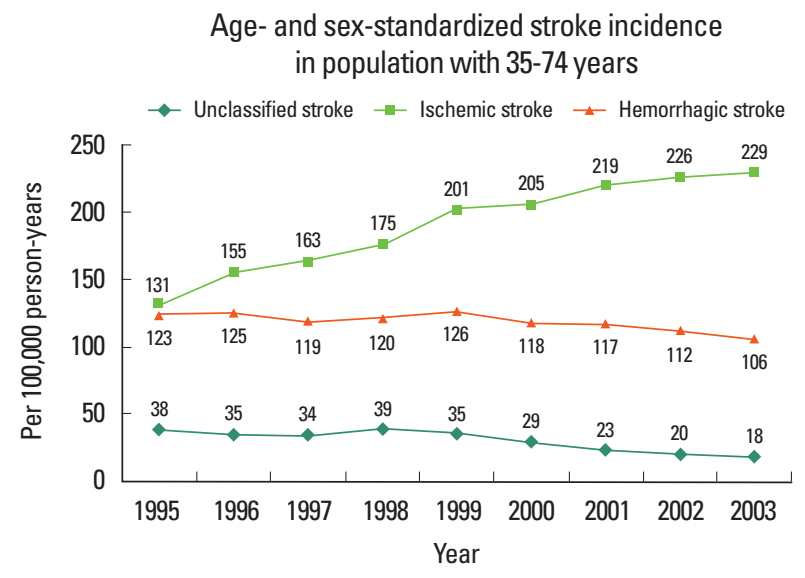

Figure 7. Age- and sex-standardized stroke incidence in population with 35-74 years. Source: Korean Center for Disease Control. Development of Strategy and Action Plans for Major Chronic Diseases Prevention and Control 2004.

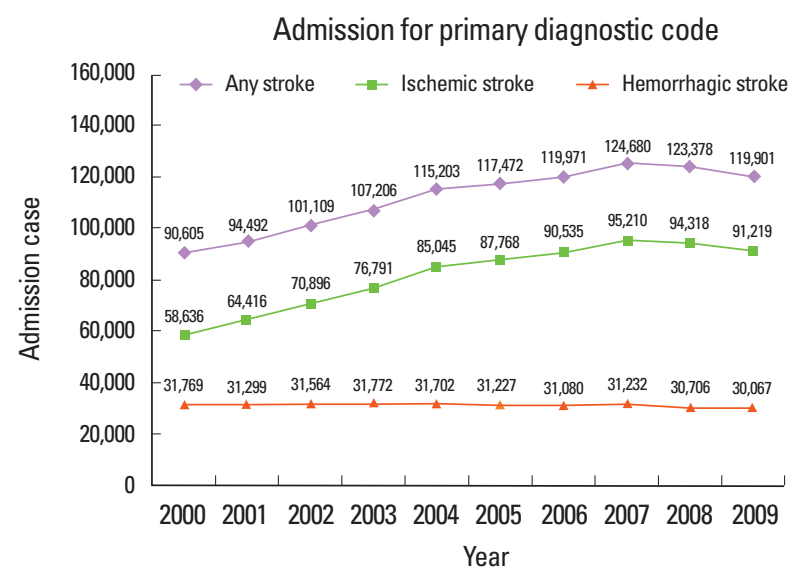

Figure 8. Admission for primary diagnostic code. Source: Korean Health Insurance Review \& Assessment Service. Report of Assessment for Quality of Acute Stroke Care in Korea 2005-2010.

by small vessel occlusion (SVO, 25.4\%) and cardioembolism (CE 17.1\%). Over the nine years, the relative proportion of cardioembolism increased, large artery atherosclerosis remained stable, and small vessel occlusion and stroke due to undetermined etiology decreased. ${ }^{4}$ That study did not include patients who were admitted to non-neurology departments or who arrived at the emergency department but were not hospitalized. However, data of the excluded patients are unlikely to substantially change the study findings.

\section{Stroke prevalence}

An estimated 795,000 Koreans $\geq 30$ years of age had a stroke diagnosed by physicians (extrapolation of prevalence data of the 2005 Korean National Health and Nutrition Examination Survey [KNHANES $]^{12}$ to 2012 population provided by Korean Statistical Information Service ${ }^{5}$ ). The KNHANES is a cross-

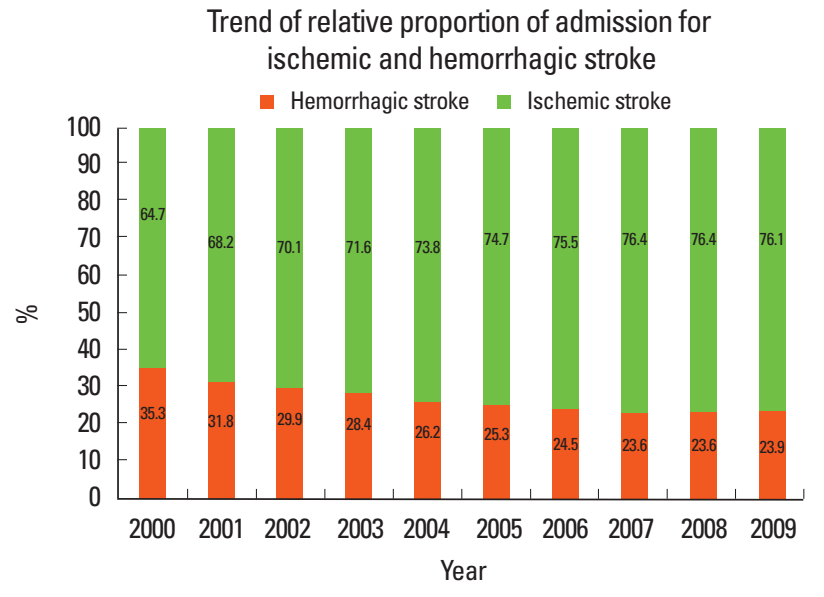

Figure 9. Trend of relative proportion of admission for ischemic and hemorrhagic stroke. Source: Korean Health Insurance Review \& Assessment Service. Report of Assessment for Quality of Acute Stroke Care in Korea 2005-2010.

sectional survey to assess the health and nutritional status of adults and children in Korea, using interviews and examinations for a representative national sample of the Korean population selected from a complex, stratified, multistage probability cluster sampling design. The age-standardized stroke prevalence in population $\geq 30$ years of age is estimated to be $1.59 \%$ (data of KNHANES 2005). For each sex, roughly 411,000 Korean men (1.64\%) and 384,000 (1.54\%) Korean women have had a stroke.

Stroke prevalence steeply increases with age. The 2005 KNHANES data demonstrated that the prevalence increased from $0.14 \%$ in the $30-39$ years old population to $6.75 \%$ in those $\geq 70$ years of age (Figure 10). ${ }^{12}$ Another study also showed that the estimated stroke prevalence increased from $0.15 \%$ for men and $0.09 \%$ for women in the population aged $\leq 45$ years to $7.21 \%$ for men and $4.98 \%$ for women $\geq 85$ years of age (Figure 11 ). ${ }^{3}$ According to the 2010 KNHANES data, the prevalence of stroke diagnosed by physicians was $2.9 \%$ (3.7\% for men, $2.3 \%$ for women) for the population $\geq 50$ years of age and $4.5 \%$ (5.6\% for men, $3.7 \%$ for women) for those $\geq 65$ years. However, there is a substantial variation in the prevalence data between 1998 and 2010, suggesting limitations of the survey studies in the accuracy of diagnostic criteria (Figure 12). ${ }^{13}$

The KNHANES 2010 report showed that the lower income population had a higher stroke prevalence than high income population in both men and women during 1998-2010 (Figure 13). The difference in stroke prevalence between low income and high income populations was generally greater in men than in women (Figures 14 and 15). ${ }^{13}$

\section{Stroke mortality}

In 2010, stroke killed 26,517 Korean people. Stroke is the 


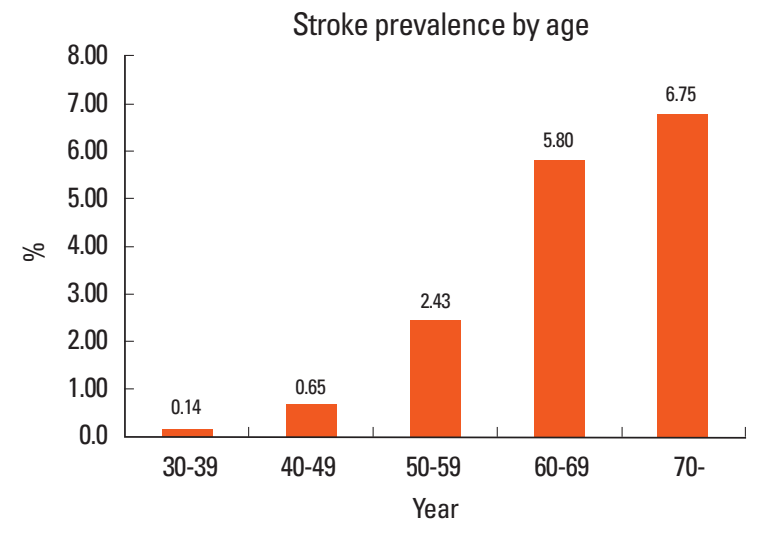

Figure 10. Stroke prevalence by age. Source: KNHANES 2005.

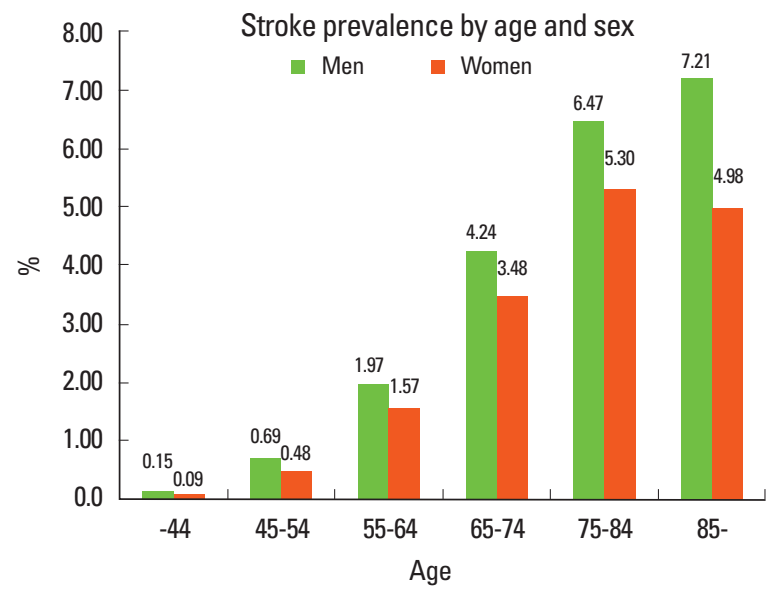

Figure 11. Stroke prevalence by age and sex. Source: Korean Center for Disease Control. Construction of National Surveillance System for Cardiovascular \& Cerebrovascular Diseases 2006.

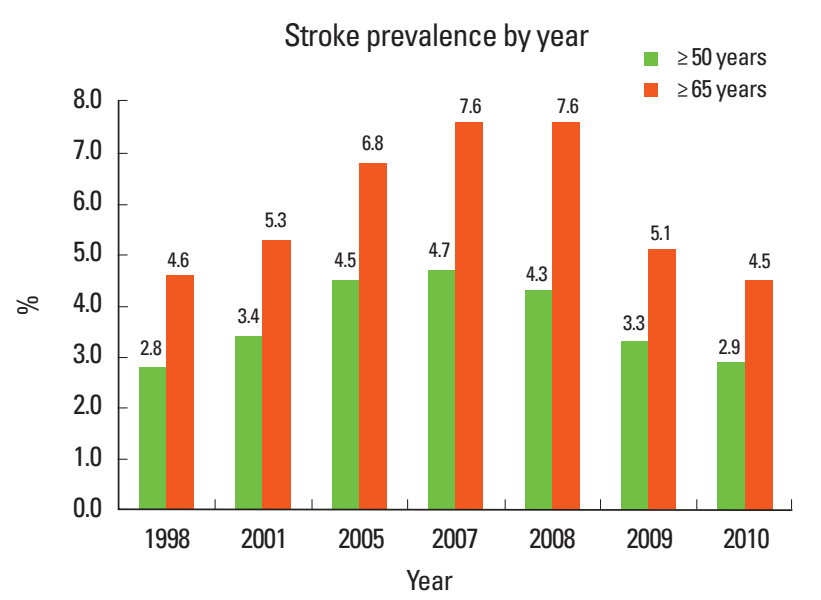

Figure 12. Stroke prevalence by year. Source: KNHANES 2010.

second leading cause of death after cancer and the first leading cause of death due to a single organ disease. Stroke death accounted for approximately one of every 10 deaths in Korea. On the average, every 20 minutes stroke kills someone. The annual

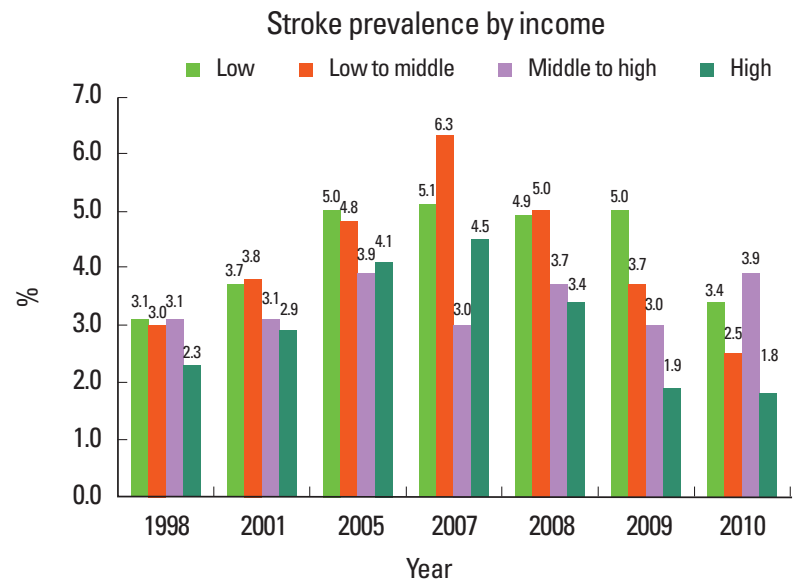

Figure 13. Stroke prevalence by income. Source: KNHANES 2010.

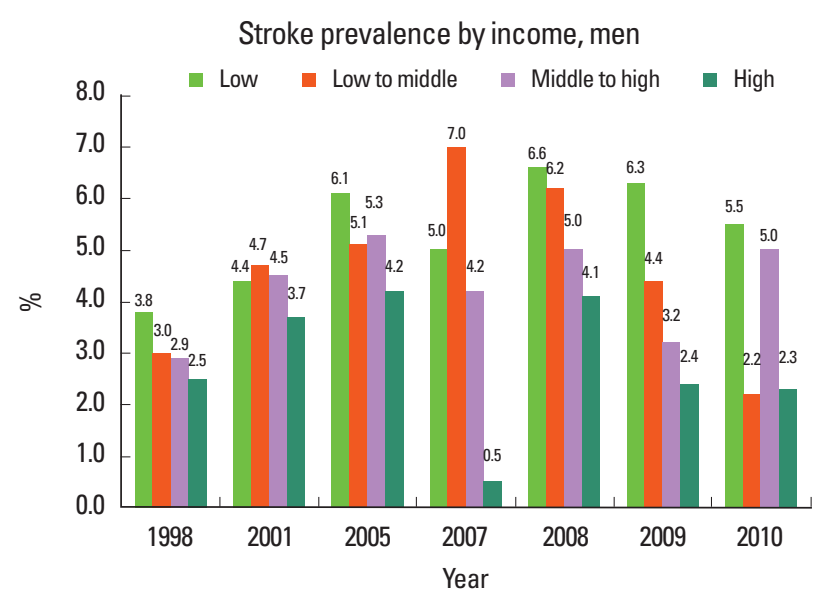

Figure 14. Stroke prevalence by income, men. Source: KNHANES 2010.
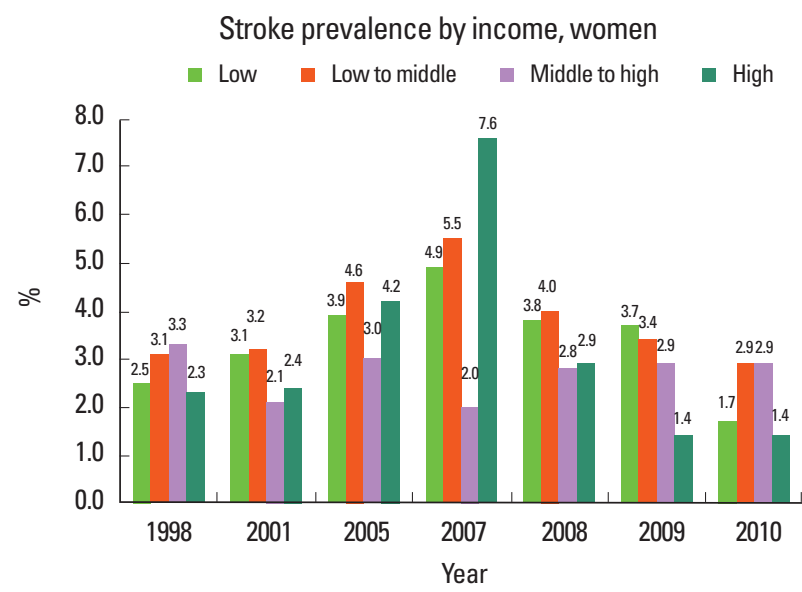

Figure 15. Stroke prevalence by income, women. Source: KNHANES 2010.

stroke mortality rate in 2010 was 53.2 per 100,000 (51.5/100,000 for men and 54.8/100,000 for women) (Figure 16). ${ }^{1416}$ More women than men die of stroke.

From 2001 to 2010, the age-standardized stroke death rate 
Trend of crude stroke mortality rate

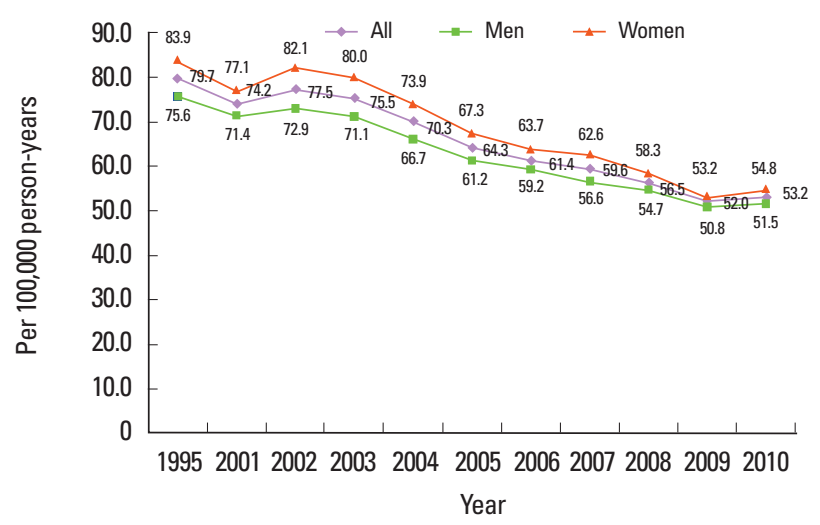

Figure 16. Trend of crude stroke mortality rate. Source: Korean Statistical Information Service (KOSIS). Annual Report on the Cause of Death Statistics, Korean Center for Disease Control. Health Behavior and Chronic Disease Statistics 2005

Trend of actual number of stroke deaths

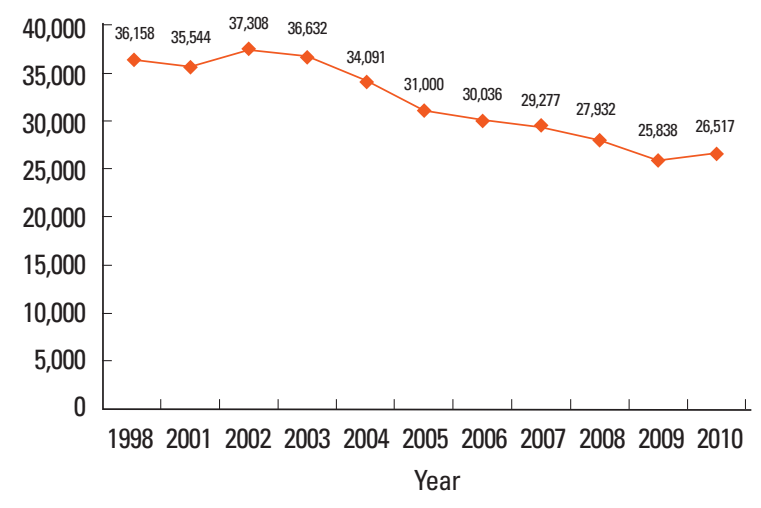

Figure 17. Trend of actual number of stroke deaths. Source: Korean Statistical Information Service (KOSIS). Annual Report on the Cause of Death Statistics, Korean Center for Disease Control. Health Behavior and Chronic Disease Statistics 2005 .

decreased by $28.3 \%$ (27.9\% for men and $28.9 \%$ for women) (Figure 16), and the actual number of stroke deaths declined by $25.4 \%$ (Figure 17). During that period, the contribution of stroke deaths to all deaths decreased from $14.7 \%$ to $10.4 \%$ (from $12.8 \%$ to $9.0 \%$ for men and from $17.1 \%$ to $12.1 \%$ for women) (Figure 18). ${ }^{14-16}$ Over the 10 years, women had a higher stroke mortality rate than men, and there was no substantial change in women-to-men ratio (from 1.08 to 1.06 ). ${ }^{14-16}$

Stroke mortality rates steeply increased with age, particularly after age 70. Compared to the population 60-69 years of age, stroke mortality rate increased by 4-fold in those 70-79 years of age and by 13 -fold in those $\geq 80$ years of age (Figure 19). ${ }^{14}$

In Korea, age-standardized stroke mortality rate has a geographic disparity (range, $27.5 / 100,000$ to $47.8 / 100,000$ ). In 2010, Jeollabuk-do, the southwest province $(47.8 / 100,000)$, and Gangwon-do, the northeast province $(47.4 / 100,000)$ rank-
Proportion of stroke death among all deaths by year

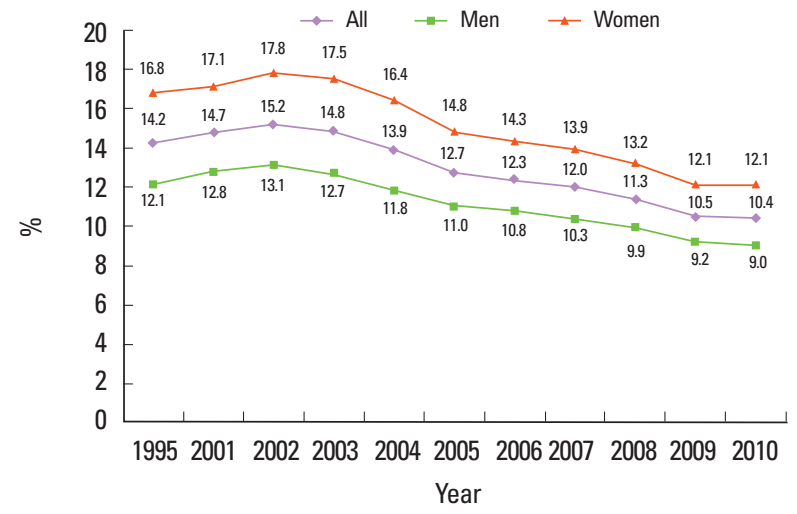

Figure 18. Proportion of stroke death among all deaths by year. Source: Korean Statistical Information Service (KOSIS). Annual Report on the Cause of Death Statistics, Korean Center for Disease Control. Health Behavior and Chronic Disease Statistics 2005.

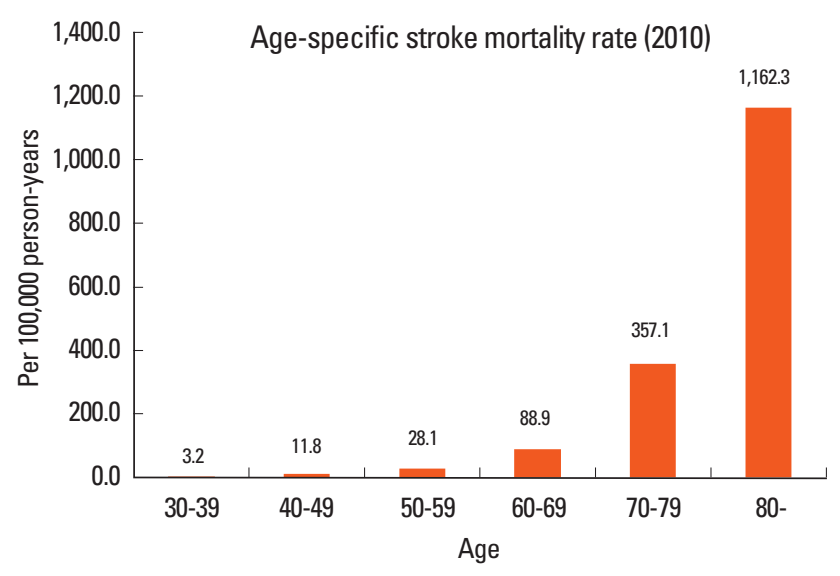

Figure 19. Age-specific stroke mortality rate (2010). Source: Korean Statistical Information Service (KOSIS). Annual Report on the Cause of Death Statistics.

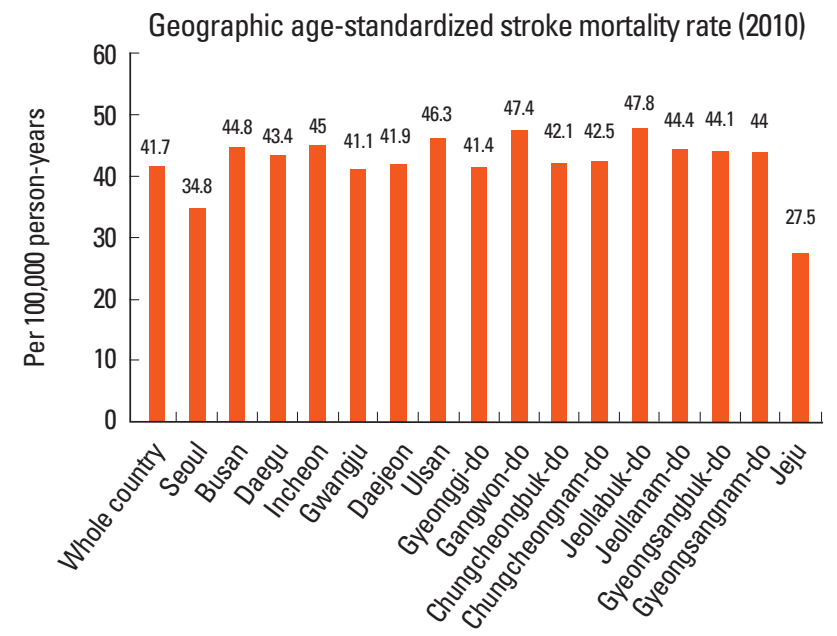

Figure 20. Geographic age-standardized stroke mortality rate (2010). Source: Korean Statistical Information Service (KOSIS). Annual Report on the Cause of Death Statistics. 
ed No. 1 and No. 2, and Jeju island had the lowest stroke mortality rate $(27.5 / 100,000)$ followed by Seoul $(34.8 / 100,000)$ (Figure 20$).{ }^{14}$ The average age-standardized mortality rate did not differ between metropoiltan cities and the other regions (42.5/100,000 vs $42.4 / 100,000)$.

\section{0-day case-fatality rate of stroke}

Stroke 30-day case-fatality rate usually indicates the proportion of deaths within 30 days after the index stroke. The Korean Center for Disease Control reported that the 30-day case-fatality rate was $23.9 \%$ (95\% confidence interval, $22.2-25.8 \%$ ) in 2004. ${ }^{3}$ Compared to ischemic stroke, hemorrhagic stroke caused a 2.4 -fold higher case-fatality rate ( $35.0 \%$ vs. $15.2 \%)$. Women had a higher case-fatality rate for any stroke and ischemic stroke than men, whereas the hemorrhagic stroke case-fatality rate was slightly higher in men than in women (Figure 21). For any stroke

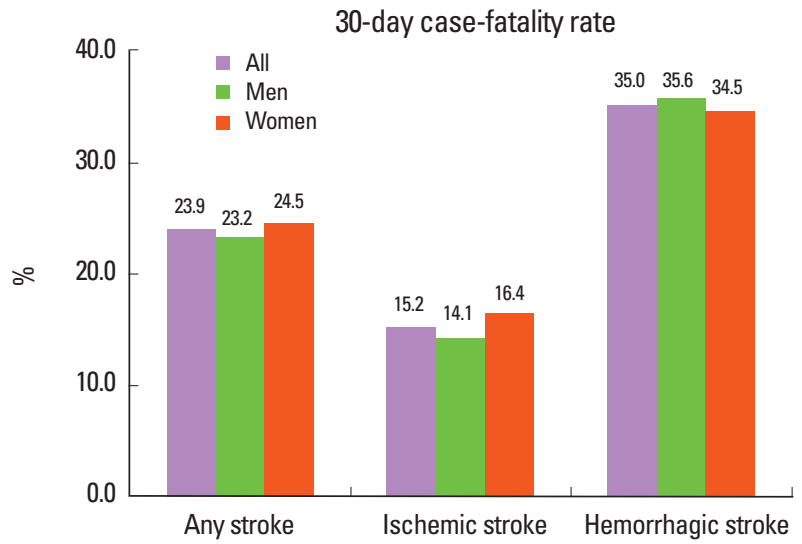

Figure 21. 30-day case-fatality rate. Source: Korean Center for Disease Control. Construction of National Surveillance System for Cardiovascular \& Cerebrovascular Diseases 2006.

30-day case-fatality rate of any stroke by age

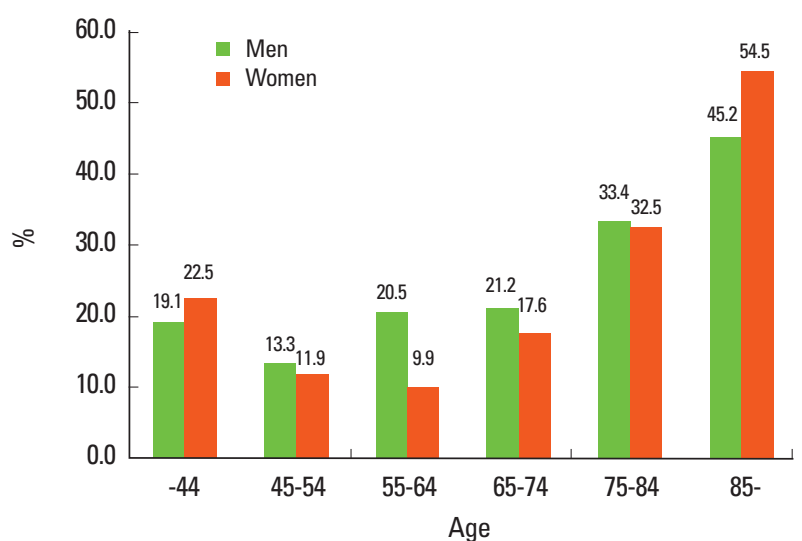

Figure 22. 30-day case-fatality rate of stroke by age. Source: Korean Center for Disease Control. Construction of National Surveillance System for Cardiovascular \& Cerebrovascular Diseases 2006. and ischemic stroke, with increasing age, the 30-day case-fatality rate generally increased in both men and women (Figures 22 and 23). However, the case-fatality rate for hemorrhagic stroke showed a complex pattern of a relatively high 30-day case-fatality rate in younger age groups (Figure 24).

In contrast, the Korean Stroke Registry Study in which 31 centers nationwide prospectively enrolled 46,098 patients with ischemic stroke from 2002 to 2010 showed that the average 30 day case-fatality rate of ischemic stroke was $4 \%$. During the period, the age-adjusted 30-day case fatality rate did not decline, but the age-adjusted 1-year mortality rate did decline significantly. ${ }^{4}$ The discrepancy in the 30-day case-fatality rate across the studies might attribute to differences in population, method, and time period, and further studies are needed to assess the current trend of 30-day stroke case-fatality rate.

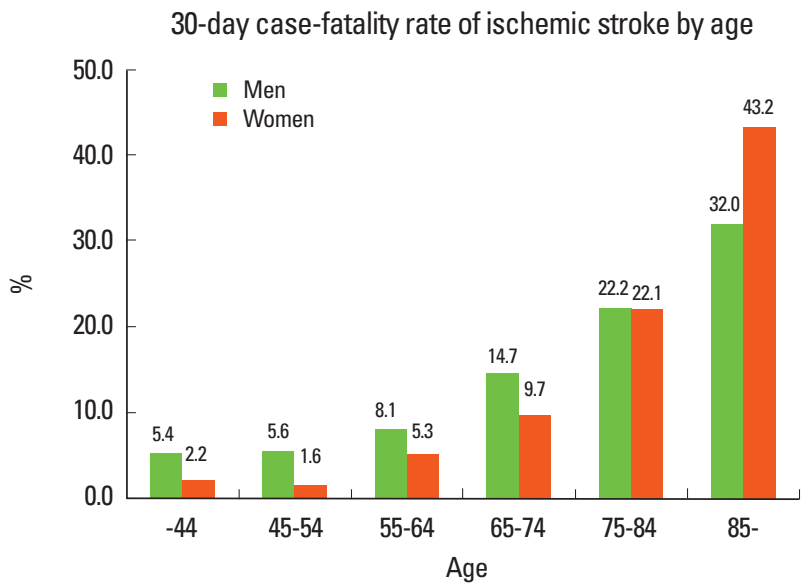

Figure 23. 30-day case-fatality rate of ischemic stroke by age. Source: Korean Center for Disease Control. Construction of National Surveillance System for Cardiovascular \& Cerebrovascular Diseases 2006.

30-day case-fatality rate of hemorrhagic stroke by age

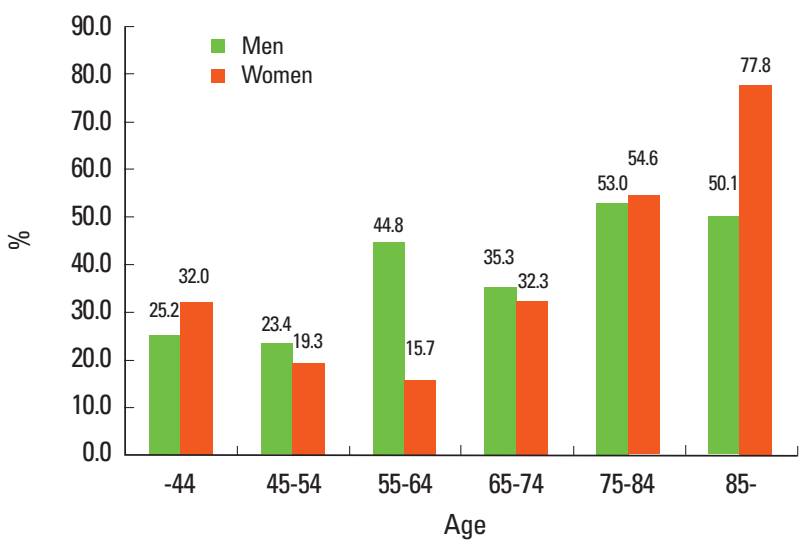

Figure 24. 30-day case-fatality rate of hemorrhagic stroke by age. Source: Korean Center for Disease Control. Construction of National Surveillance System for Cardiovascular \& Cerebrovascular Diseases 2006. 


\section{In-hospital mortality rate}

Acute stroke treatment has advanced dramatically over the last decade, and quality of stroke care in Korean hospitals has substantially improved. The Health Care Quality Indicators Project data demonstrated that, among OECD countries, Korea had the lowest in-hospital 30-day case-fatality rate for ischemic stroke (crude rate, $2.5 \%$; age-sex standardized rate, $1.8 \%$ ) and ranked third lowest for hemorrhagic stroke (crude rate, 10.2\%; age-sex standardized rate, 9.8\%) in 2009 (Figures 25 and 26). ${ }^{17}$ Although the analysis did not adjust for stroke severity, the single most important determinant of outcome, these findings suggest that hospitals in Korea are providing a high quality of acute stroke care.

According to the Report of Assessment for Quality of Acute Stroke Care in Korea 2010, the crude in-hospital mortality rate of acute stroke admission was $8.3 \%$ for any strokes, $4.3 \%$ for ischemic strokes, and $17.5 \%$ for hemorrhagic stroke. The crude mortality rates were stable during the period of 2005-2010 (Figure 27). ${ }^{9}$

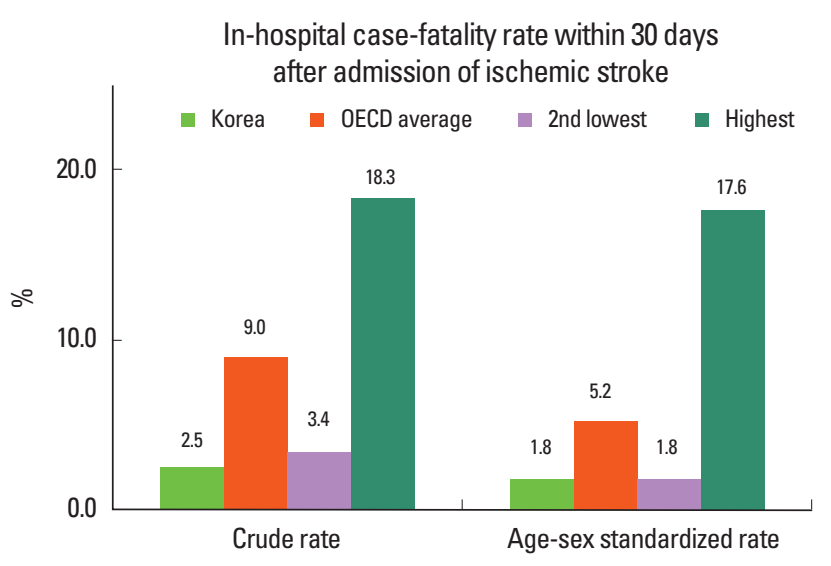

Figure 25. In-hospital case-fatality rate within 30 days after admission of ischemic stroke. Source: OECD (2011), Health at a Glance 2011: OECD Indicators, OECD Publishing. (http://dx.doi.org/10.1787/health_glance-2011-en).

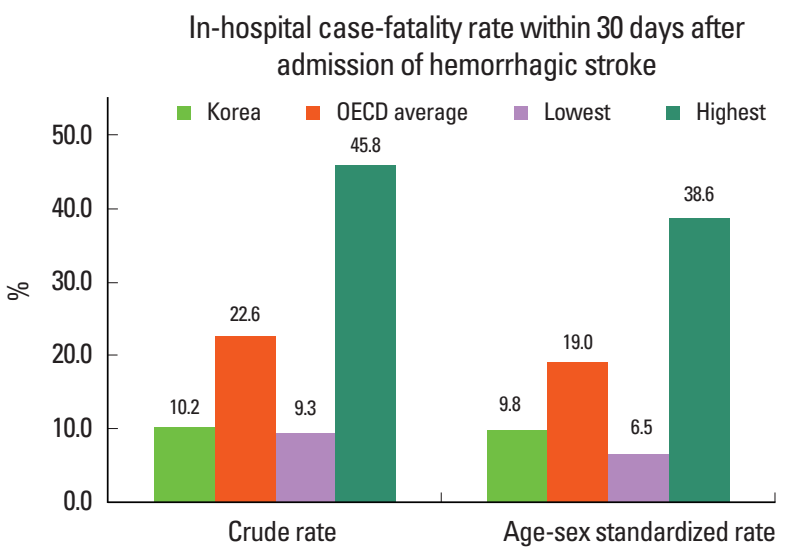

Figure 26. In-hospital case-fatality rate within 30 days after admission of hemorrhagic stroke. Source: OECD (2011), Health at a Glance 2011: OECD Indicators, OECD Publishing. (http://dx.doi.org/10.1787/health_glance-2011-en).

\section{0-day functional outcome after stroke}

Since stroke disables as well as kills people, disability after stroke is an important burden to patients, their family, and society. Therefore, measuring burden of stroke should incorporate the post-stroke disability as well as mortality. Since more than $90 \%$ of stroke recovery occurs in the first 3 months in most stroke patients, ${ }^{18}$ residual post-stroke disability is usually assessed at 90 days after stroke. For a disability outcome measure, modified Rankin Scale (mRS) is most widely favored and recommended by researchers and regulatory authorities. ${ }^{19,20}$

For a nationwide representative population cohort, fine-grained 90-day mRS disability after stroke has not been evaluated in Korea as well as in most other countries, but several hospitalbased registry studies have reported 90 -day mRS disability outcome. For ischemic stroke, $49-66 \%$ of patients had an excellent outcome of mRS 0-1 and 63-80\% had a good outcome of mRS $0-2$. Mortality rates at 90 days ranged $3-7 \%$ across the studies. ${ }^{21-23}$

For hemorrhagic stroke, a single center study reported 3-month mRS outcome for 585 primary intracerebral hemorrhage. ${ }^{24}$ As expected, hemorrhagic strokes had worse 90-day outcomes than ischemic strokes. Twenty-nine \% of patients achieved independent outcome of mRS 0-3, and $16.9 \%$ were dead at 90 days.

\section{Disability-adjusted life years (DALY) lost due to stroke}

The DALY is a formal metric of the World Health Organization Global Burden of Disease Project (WHO-GBDP) to measure regional and global burdens of hundreds of diseases. The DALY incorporates disability and mortality into a single metric of healthy life years lost, whereby one DALY lost indicates one

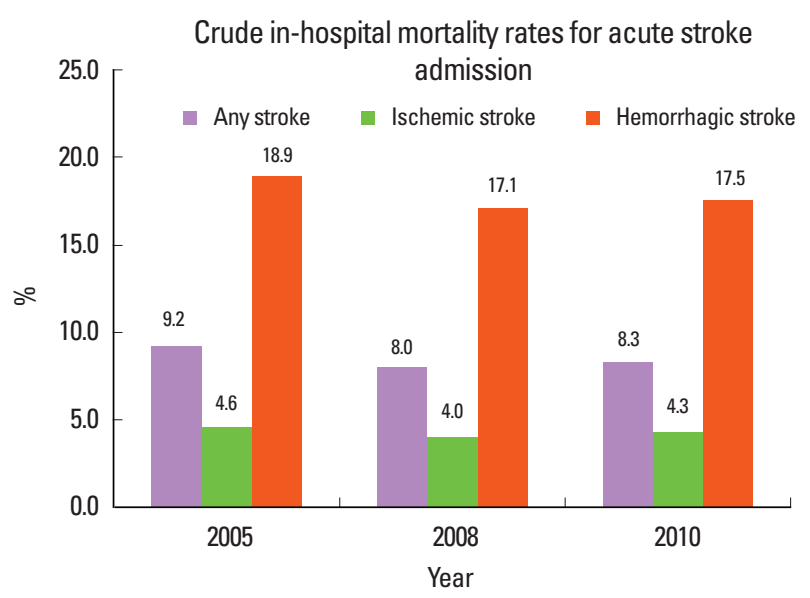

Figure 27. Crude in-hospital mortality rates for acute stroke admission. Source: Korean Health Insurance Review \& Assessment Service. Report of Assessment for Quality of Acute Stroke Care in Korea 2010. 
year loss of healthy life, free of disability. ${ }^{25}$

In high income countries, the DALY lost to ischemic heart disease is usually greater than the DALY lost to stroke. However, among high income countries, Korea ranked No. 1 of greater DALY lost to stroke than to ischemic heart disease. ${ }^{26}$ In the WHO-GBDP report, Korea is categorized into a group wherein the DALY lost to stroke is between 641 and 880 per 100,000 person-years. More specifically, the sex- and age-adjusted DALY lost per 100,000-years was 703, and the unadjusted DALY lost was 855 (obtained from a personal communication with S. Claiborne Johnston, who is the first author of a related article ${ }^{27}$ ). Therefore, nationwide annual DALY lost to stroke would be about 344,000

For ischemic stroke, the projected nationwide DALY lost due to 64,688 ischemic strokes in 2004 was 234,399 (121,482 for men and 113,244 for women), and the DALY lost per 100,000 person-years was 483 (500 for men and 469 for women). The DALY lost of 65-74 years contributed $37.9 \%$ to overall DALY lost, followed by the age groups of 75-84 and 55-64 years. ${ }^{28}$

\section{Economic cost of stroke}

According to estimates from the Korean National Health Insurance Claims Database for 2005, the nationwide total cost for stroke was 3,737 billion Korean won (KRW) (US\$3.3 billion) which included direct costs of 1,130 billion KRW (US\$1.0 billion) and indirect costs of 2,606 billion KRW (US $\$ 2.3$ billion). ${ }^{29}$

In 2009, the total cost for admission and out-patient clinic for stroke care paid by the Korean Health Insurance Agency was 870.3 billion KRW ( 545.2 billion KRW for ischemic stroke and 325.1 billion KRW for hemorrhagic stroke), which increased by

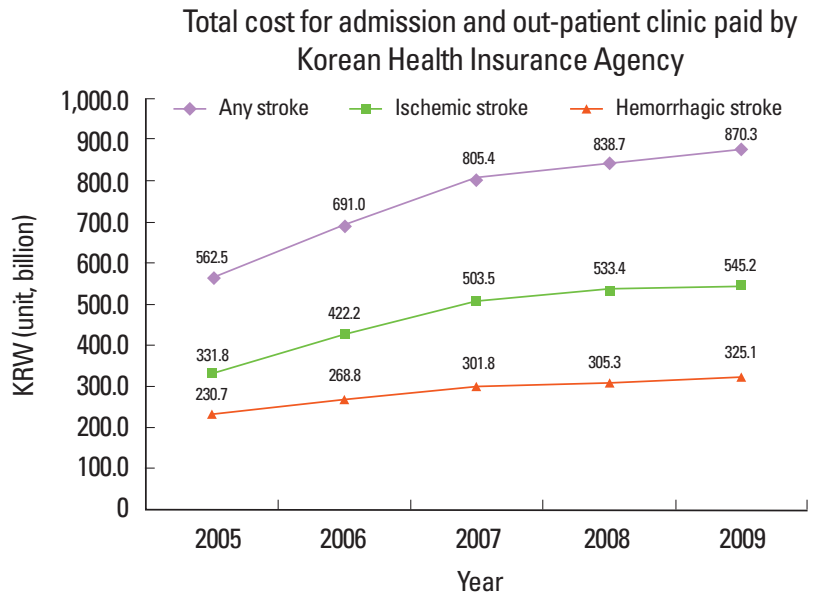

Figure 28. Total cost for admission and out-patient clinic paid by Korean Health Insurance Agency. Source: Korean Health Insurance Review \& Assessment Service. Report of Assessment for Quality of Acute Stroke Care in Korea 20052010.

\section{7\% from 2005 (Figure 28).}

For each stroke admission, the average costs in 2009 were 4.92 million KRW for any stroke, 3.95 million KRW for ischemic stroke, and 7.82 million KRW for hemorrhagic stroke, which gradually increased during the period of 2005-2009 (Figure 29). Compared with an ischemic stroke admission, a hemorrhagic stroke admission carries a 2 -fold greater cost. ${ }^{7-9}$

The average lifetime cost for men who had a first stroke was estimated to be 200.7 million KRW at age 45, 81.9 million KRW at age 55, and 16.4 million KRW at age 65. For women, it was estimated to be 75.7 million KRW at age 45, 39.2 million KRW at age 55, and 19.3 million KRW at age 65 . While strokes in those 45-64 years of age accounted for only $30 \%$ of all strokes, this age group incurred $75 \%$ of the total national lifetime costs of stroke. ${ }^{30}$ However, the study might underestimate the lifetime cost since it did not consider the productivity loss of housewives and loss due to disability.

\section{Risk factors}

\section{Hypertension}

Hypertension (HT) is the most important well-documented and modifiable risk factor for stroke. For blood pressure over $115 / 75 \mathrm{~mm} \mathrm{Hg}$, an increase in systolic blood pressure (SBP) of $20 \mathrm{mmHg}$ or in diastolic blood pressure (DBP) of $10 \mathrm{mmHg}$ was associated with a more than 2 -fold increased risk of stroke mortality. ${ }^{31}$ In a meta-analysis of clinical trials, antihypertensive treatment reduced the risk of stroke by $32 \%$ (95\% CI, 24-36\%). ${ }^{32}$

\section{Prevalence}

$\mathrm{HT}$ is defined as $\mathrm{SBP} \geq 140 \mathrm{~mm} \mathrm{Hg}$ or $\mathrm{DBP} \geq 90 \mathrm{~mm} \mathrm{Hg}$ or

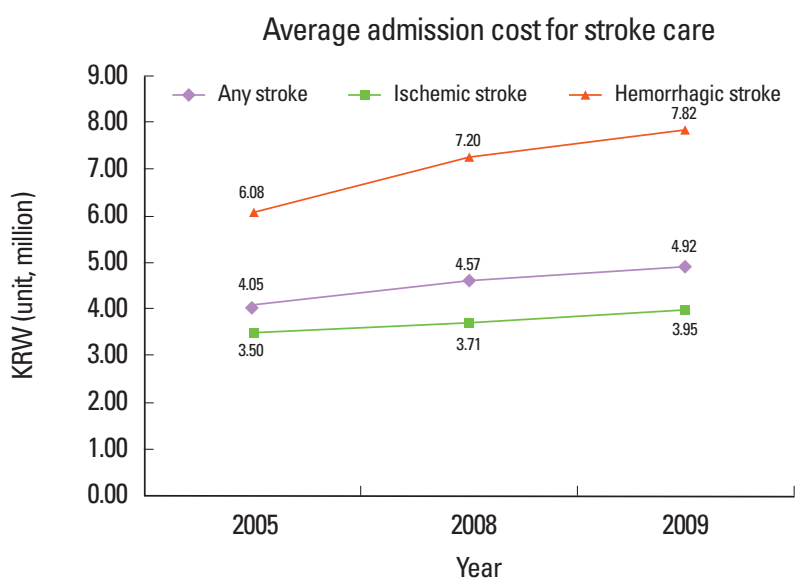

Figure 29. Average admission cost for stroke care. Source: Korean Health Insurance Review \& Assessment Service. Report of Assessment for Quality of Acute Stroke Care in Korea 2005-2010. 
taking antihypertensive medicine.

One in 3-4 Korean adults $\geq 30$ years of age has HT, and approximately 7,500,000 adults $\geq 30$ years of age have HT (data from 2010 KNHANES adjusted to 2005 standardized population)..$^{13}$ The age-adjusted prevalence of HT decreased during 1998 to 2007, but slightly increased from 2007 to 2008, and then remained stable since 2008 (Figure 30). ${ }^{13}$

Data from NHANES 2010 showed that $28.9 \%$ of people aged $\geq 30$ years had HT. HT was more prevalent in men than in women in those $\geq 30$ years of age ( $30.1 \%$ vs. $27.7 \%$ ). Until 59 years of age, a higher percentage of men than women have HT, but from 60 years of age HT was more prevalent in women than in men (Figure 31). ${ }^{13}$ In the population $<50$ years of age, men had twice the prevalence of HT than women.

Data from NHANES 2010 showed that the prevalence of HT in men increased until 60-69 years and then slightly decreased, and the HT prevalence in women monotonically increased with age. In men of 30-59 years, the prevalence of HT almost doubled with every 10-year increase of age. In women 30-69 years

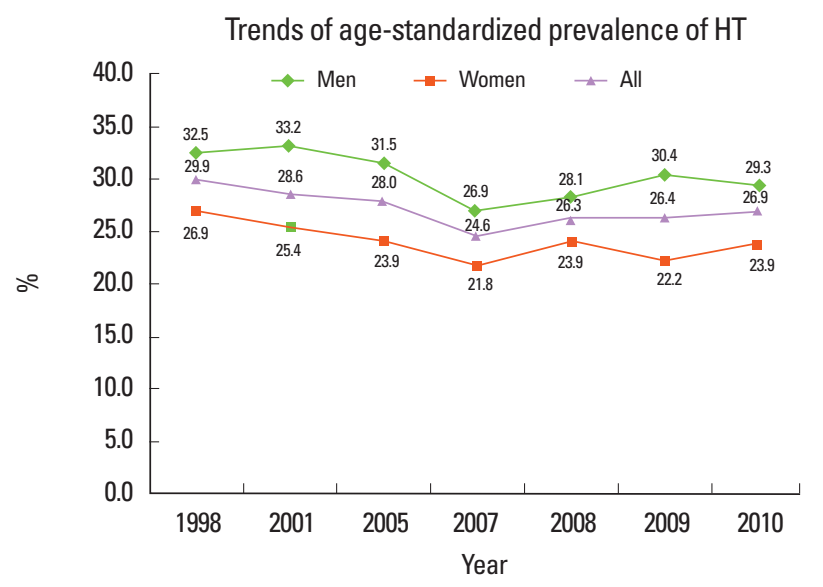

Figure 30. Trends of age-standardized prevalence of HT. Source: KNHANES 2010.

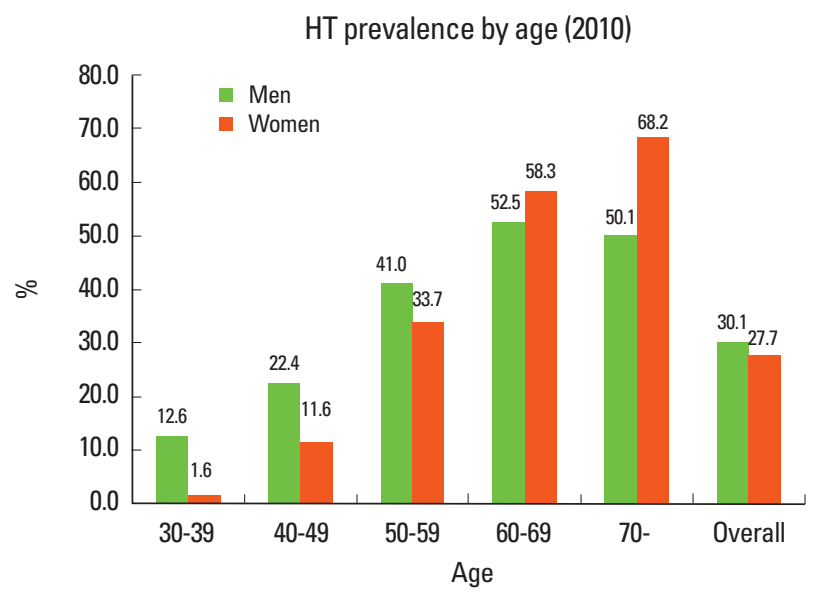

Figure 31. HT prevalence by age (2010). Source: KNHANES 2010. of age, the HT prevalence increased by nearly 10 -fold from 30 39 years to $40-49$ years, by almost 3-fold from $40-49$ years to 50-59 years, and by a 1.7-fold from 50-59 years to $60-69$ years (Figure 31). Compared to worldwide prevalence data, ${ }^{33}$ the HT prevalence in Korea is lower in men 30-49 years old and $\geq 70$ years and in women aged $30-59$ years and $\geq 70$ years, but higher in men 50-69 years old and in women of 60-69 years.

\section{Blood pressure}

Data from KNHANES 2010 showed that with increasing age, SBP increased monotonically, and DBP increased until 60 years and then decreased in both men and women. For people of age less than 60 years, men had a higher SBP than women, but from age $60 \mathrm{SBP}$ was higher in women than in men. DBP had a similar trend (Figure 32). ${ }^{13}$

\section{Awareness, treatment, and control}

Data from KNHANES 2008-2010 showed that among people aged $\geq 30$ years with hypertension, $67.9 \%$ were aware of their HT (diagnosed by physicians), $61.9 \%$ were on regular treatment (taking medication $\geq 20$ days per month), and $43.6 \%$ had their blood pressure under control (SBP $<140 \mathrm{mmHg}$ and DBP was $<90 \mathrm{mmHg}) .{ }^{13}$ The awareness, treatment, and control of HT improved compared to data of KNHANES 20072009 (Figure 33),$^{34}$ but still remained less than those of the US population. ${ }^{35}$

Women had higher percentages of awareness, treatment, and control of HT than men for all age groups. Younger age groups showed lower percentages of awareness, treatment, and control of HT than elderly groups. In people 30-39 years of age, less than $30 \%$ were aware of their HT, less than $20 \%$ had regular treatment, and about one of ten had their blood pressure under control (Figure 34).

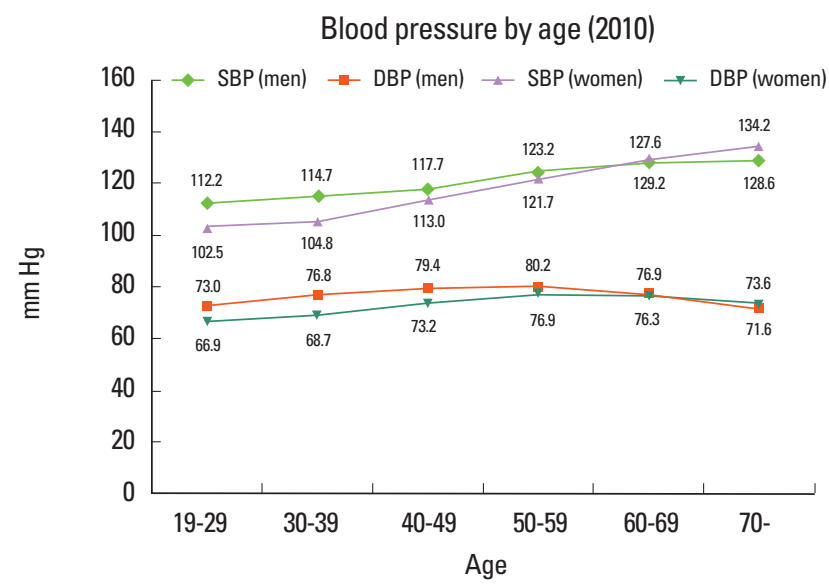

Figure 32. Blood pressure by age (2010). Source: KNHANES 2010. 


\section{Smoking}

\section{Prevalence in adults}

From 1998 to 2007, the age-standardized prevalence of current smoking in Korean men $\geq 19$ years of age declined from $66.3 \%$ to $45.3 \%$, but increased slightly from 2007 to 2010 (48.3\%). For women, smoking prevalence remained low (ranging 5.27.4\%) (Figure 35). ${ }^{13}$ The smoking prevalence from KNHANES 2010 data (48.1\% in men and $6.1 \%$ in women) was substantially higher in men and substantially lower in women compared to the US population (21.2\% in US men and $17.5 \%$ in US women).$^{35}$ Data from KNHANES 2010 showed that the smoking prevalence in men was highest in 30-39 years of age (60.9\%) and then decreased with age. However, more than half of men $19-59$ years of age were still smoking (Figure 36$){ }^{13}$

Trends of awareness, treatment, and control of HT

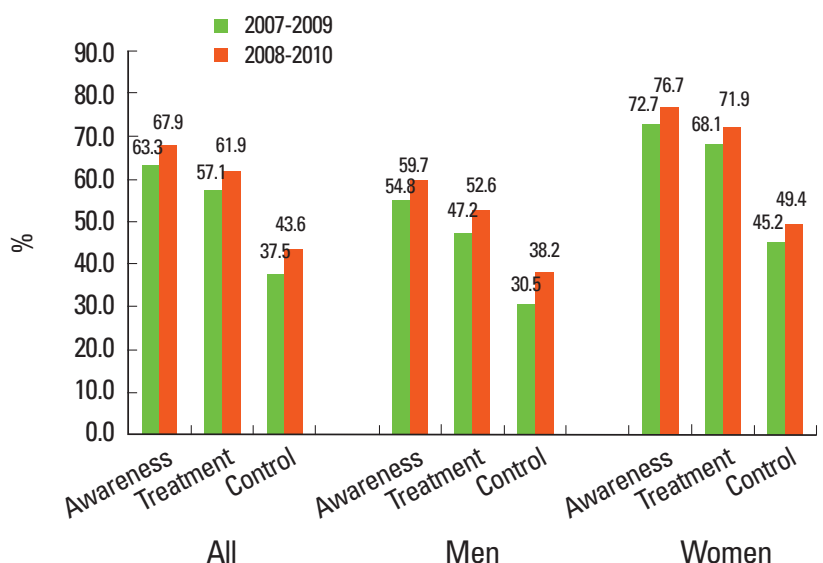

Figure 33. Trends of awareness, treatment, and control of HT. Source: KNHANES 2010.

Awareness, treatment, control of $\mathrm{HT}$ by age and sex (2008-2010)

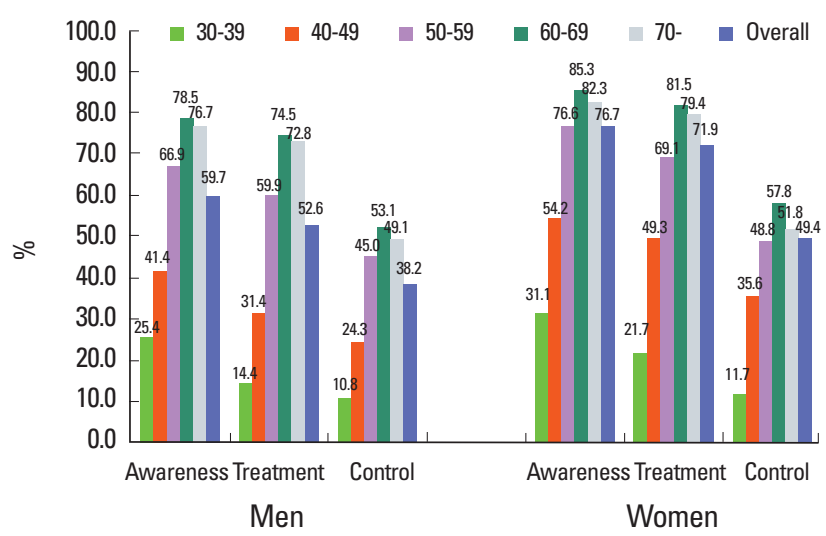

Figure 34. Awareness, treatment, control of HT by age and sex (2008-2010). Source: KNHANES 2010

\section{Secondhand smoke}

Secondhand smoke also increases the risk of stroke. In KNHANES 2010, secondhand smoke was defined as inhalation of smoke in home or office by persons other than intended active smokers. From 2005 to 2010, the percentage of secondhand smoke slightly increased from $36.4 \%$ to $39.7 \%{ }^{13}$

\section{Diabetes mellitus}

People with diabetes mellitus (DM) have an increased risk of stroke. In patients with type 2 diabetes, each $1 \%$ increase in $\mathrm{Hb}$ Alc was associated with a $12 \%$ increase of relative risk of stroke. ${ }^{36}$

\section{Prevalence}

In KNHANES 2010, DM was defined as fasting glucose $\geq 126$ $\mathrm{mg} / \mathrm{d}$, diagnosis by physicians, or being treated with oral hypoglycemic agents or insulin.

One in ten Korean adults $\geq 30$ years of age have DM, and

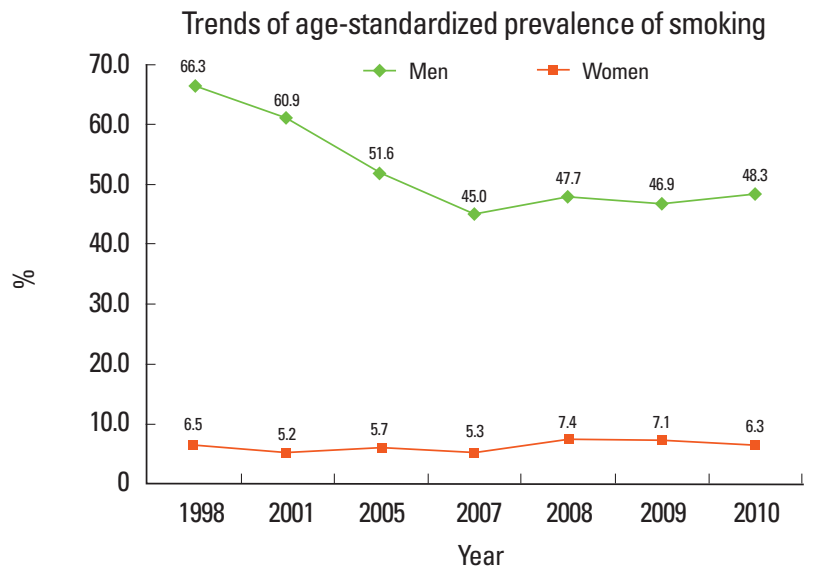

Figure 35. Trends of age-standardized prevalence of smoking. Source: KNHANES 2010

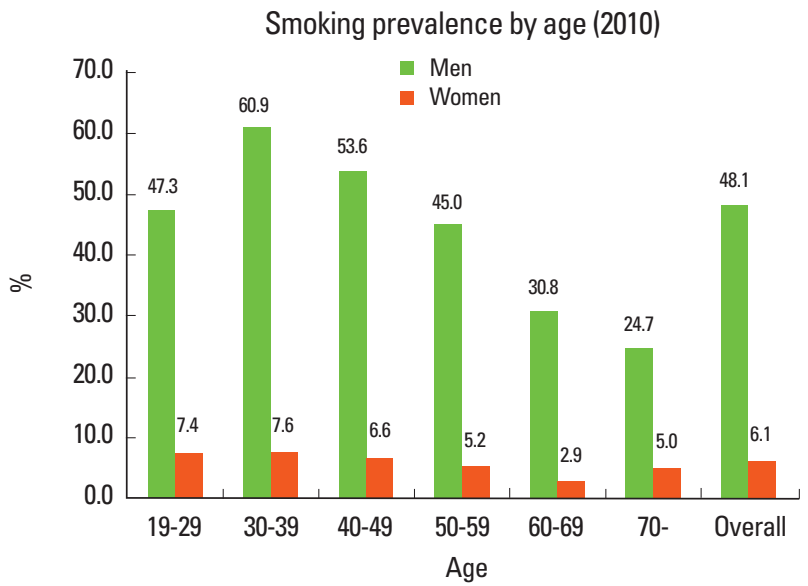

Figure 36. Smoking prevalence by age (2010). Source: KNHANES 2010. 
around 2,730,000 adults have DM (data from 2010 KNHANES adjusted to 2005 standardized population). ${ }^{13}$ The age-standardized prevalence of DM increased from $8.6 \%$ in 2001 to $9.7 \%$ in 2010, and the increase was greater in men (from $9.5 \%$ in 2001 to $11.0 \%$ in 2010) than in women (from $7.9 \%$ in 2001 to $8.3 \%$ in 2010) (Figure 37). ${ }^{13}$

Data from KNHANES 2010 showed that $10.1 \%$ of population $\geq 30$ years of age had DM. DM was more prevalent in men than in women (11.3\% vs. 9.0\%). Except for those $60-69$ years of age, the prevalence of $\mathrm{DM}$ was higher in men than in women (Figure 38) ${ }^{13}$ Notably, in those $50-59$ years of age, men had twice the prevalence of DM than women.

Data from KNHANES 2010 showed that the prevalence of DM in men increased until age 59 , then slightly decreased in those aged 60-69 years, and then increased again after age 70. In contrast, in women, the prevalence of DM monotonically increased with aging. The steepest increase of DM prevalence was observed in 50-59 years for men and 60-69 years for women.

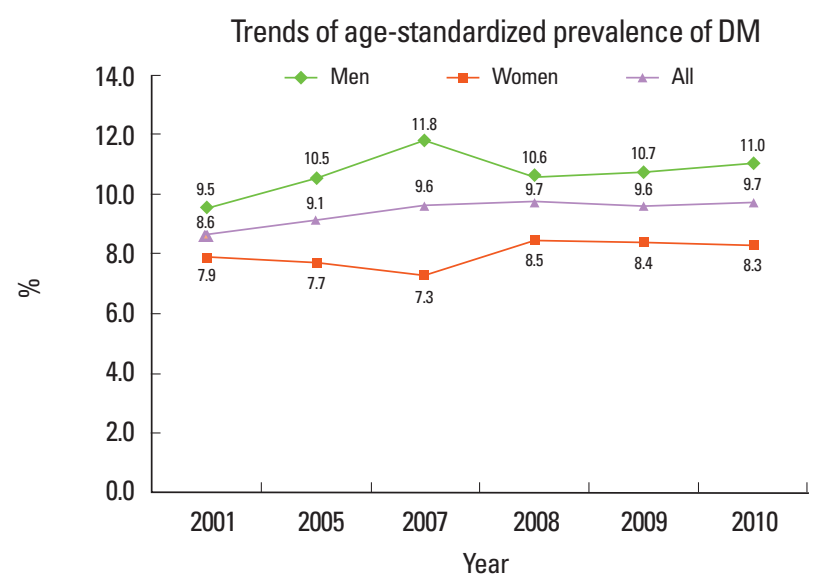

Figure 37. Trends of age-standardized prevalence of DM. Source: KNHANES 2010.

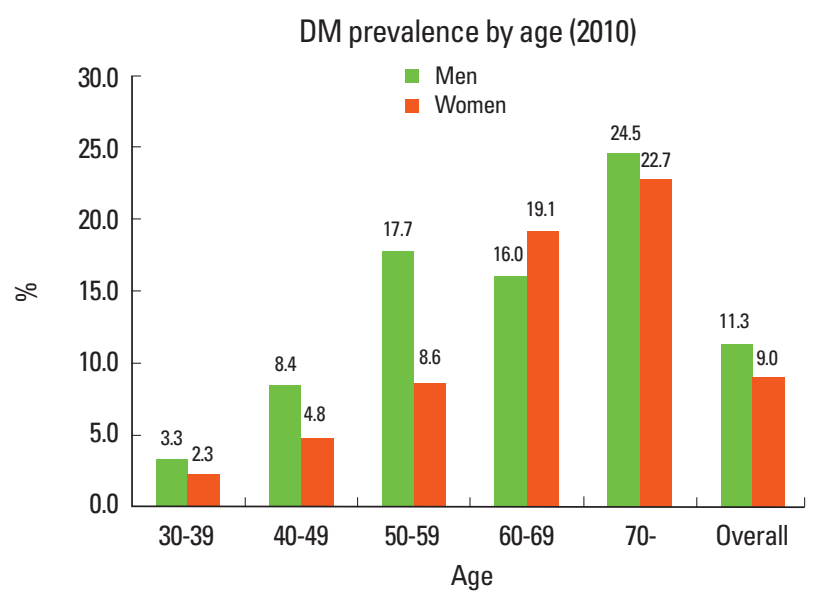

Figure 38. DM prevalence by age (2010). Source: KNHANES 2010.

\section{Blood glucose}

According to data from KNHANES 2010, blood glucose level generally increased with aging. In women, as age increased, blood glucose level increased monotonically whereas in men blood glucose level increased until 50-59 years of age and then decreased after 60 years. In those less than 70 years old, men had a higher blood glucose level than women, but from age 70 blood glucose level was higher in women than in men (Figure 39).

\section{Awareness, treatment, and control}

Data from KNHANES 2008-2010 showed that of people with $\mathrm{DM} \geq 30$ years old, $73.0 \%$ were aware of their DM (diagnosed by physicians), $59.1 \%$ were on regular treatment (treatment with oral hypoglycemic agents or insulin), and $28.1 \%$ had their DM under control $(\mathrm{HbAlc}<6.5 \%) .{ }^{13}$ The awareness, treatment, and control of DM were comparable to data of KNHANES 2007-2009 (Figure 40). ${ }^{34}$

Data from KNHANES 2010 showed that the percentages of awareness and treatment were higher in women than in men (awareness, $77.6 \%$ vs. $69.0 \%$; treatment, $64.0 \%$ vs. $54.9 \%$ ), but the percentage of control was higher in men than in women $(30.1 \%$ vs. $25.8 \%)$. In men, younger age groups, particularly those 30-39 years of age, showed substantially low percentages of awareness, treatment, and control. In women, the percentage of awareness was generally high for all age groups. However, in young women, the percentages of treatment and control were very low given their high percentage of awareness (Figure 41).

\section{Dyslipidemia}

Despite the inconsistent epidemiological findings of the association between hypercholesterolemia and stroke, lowering cholesterol with statins reduces the risk of ischemic stroke in patients with high risk for stroke or with non-cardioembolic

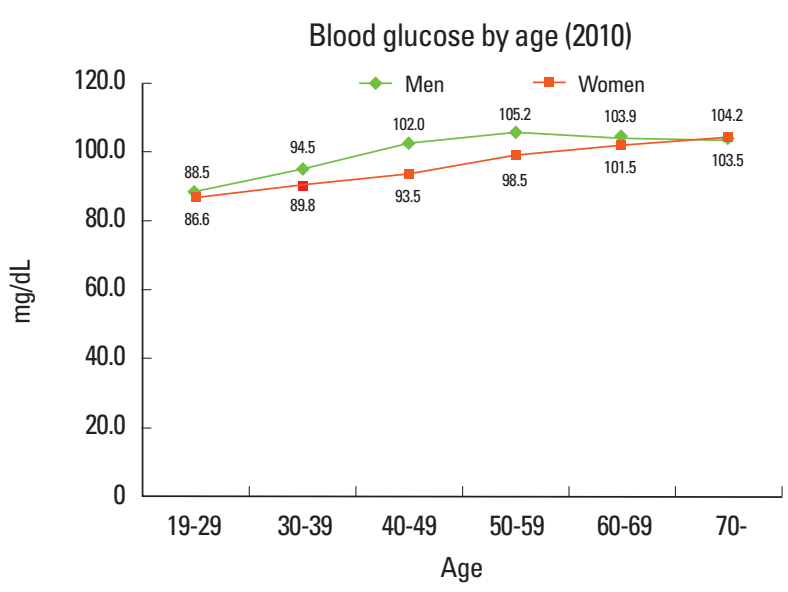

Figure 39. Blood glucose by age (2010). Source: KNHANES 2010. 
stroke. Each $1 \mathrm{mmol} / \mathrm{L}(39 \mathrm{mg} / \mathrm{dL})$ decrease of LDL-cholesterol with statin treatment reduced the relative risk of stroke by $21.1 \%{ }^{37}$

\section{Prevalence}

In KNHANES 2010, hypercholesterolemia was defined as total cholesterol $\geq 240 \mathrm{mg} / \mathrm{dL}$ or taking cholesterol lowering medication, low HDL-cholesterol as $<40 \mathrm{mg} / \mathrm{dL}$, and hypertriglyceridemia as $\geq 200 \mathrm{mg} / \mathrm{dL}$.

Among Korean adults $\geq 30$ years of age, one in seven has hypercholesterolemia, one in four has low HDL-cholesterol, and one in six has hypertriglyceridemia. Approximately 3,800,000 adults $\geq 30$ years of age have hypercholesterolemia, about 7,400,000 have low-HDL, and 4,700,000 have hypertriglyceridemia (data from 2010 KNHANES adjusted to 2005 standardized population). ${ }^{13}$ The age-standardized prevalence of hyper-

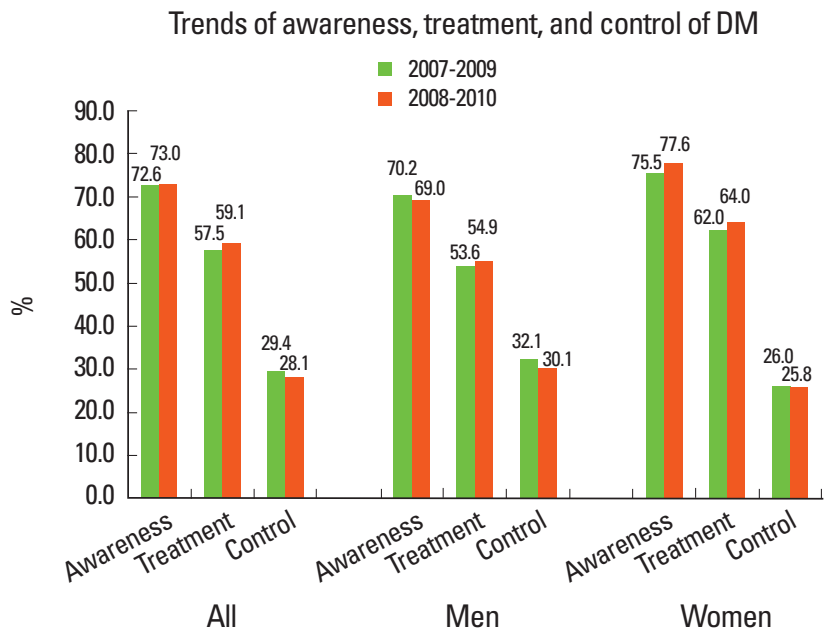

Figure 40. Trends of awareness, treatment, and control of DM. Source: KNHANES 2010

Awareness, treatment, control of DM by age and sex (2008-2010)

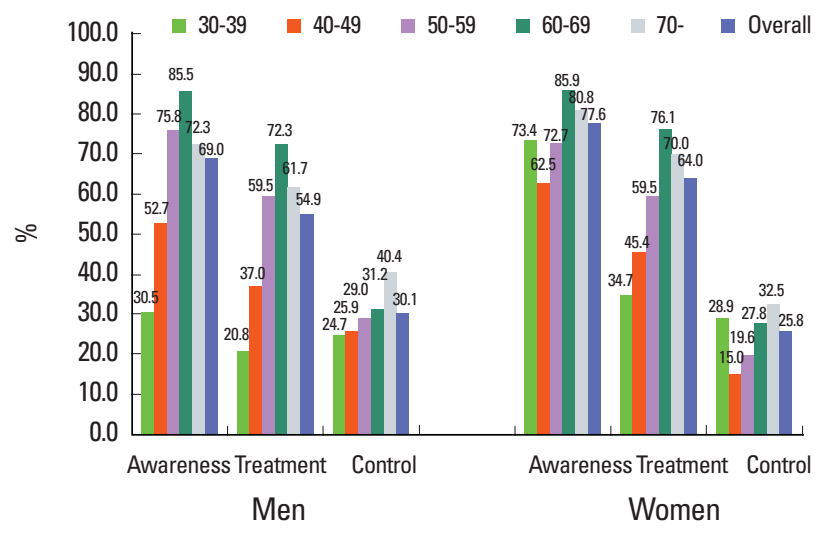

Figure 41. Awareness, treatment, control of DM by age and sex (2008-2010) Source: KNHANES 2010. cholesterolemia increased from $10.0 \%$ in 1998 to $13.5 \%$ in 2010, and the increase was greater in men (from $8.7 \%$ in 1998 to $13.0 \%$ in 2010 ) than in women (from $10.6 \%$ in 1998 to $13.4 \%$ in 2010). The age-standardized prevalence of hypertriglyceridemia increased during 1998 to 2001 and then remained stable since 2005, whereas that of low HDL-cholesterol did not change substantially since 2008 (Figure 42). ${ }^{13}$

Data from KNHANES 2010 showed that $14.1 \%$ of population with $\geq 30$ years of age had hypercholesterolemia. Hypercholesterolemia was more prevalent in women than in men (14.9\% vs. $13.4 \%)$. Until 49 years of age, the prevalence was higher in men than in women, but from 50 years hypercholesterolemia was more prevalent in women than in men (Figure 43)..$^{13}$ In the population $\geq 60$ years of age, the prevalence of hypercholesterolemia in women was more than two times higher than in men. Low HDL-cholesterol less than $40 \mathrm{mg} / \mathrm{dL}$ was observed in $26.5 \%$ of population $\geq 30$ years of age, and it was

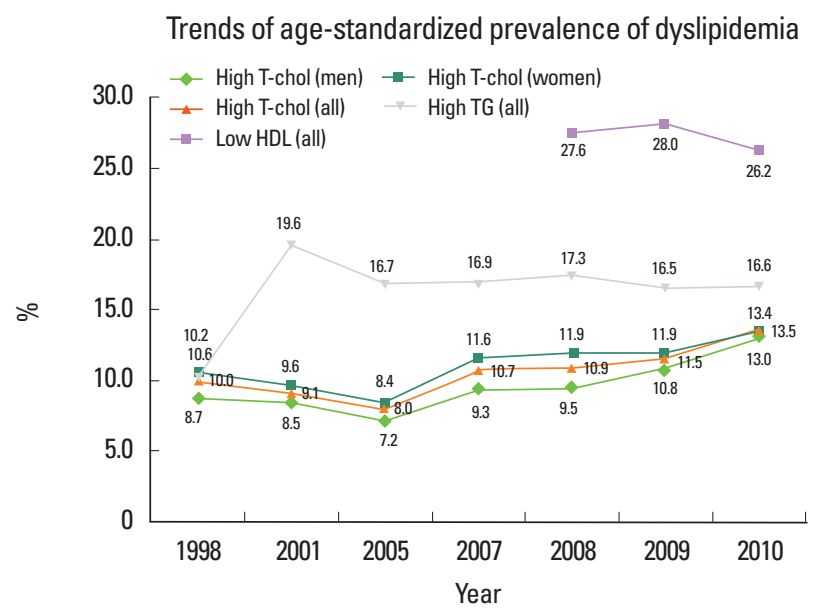

Figure 42. Trends of age-standardized prevalence of dyslipidemia. Source: KNHANES 2010.

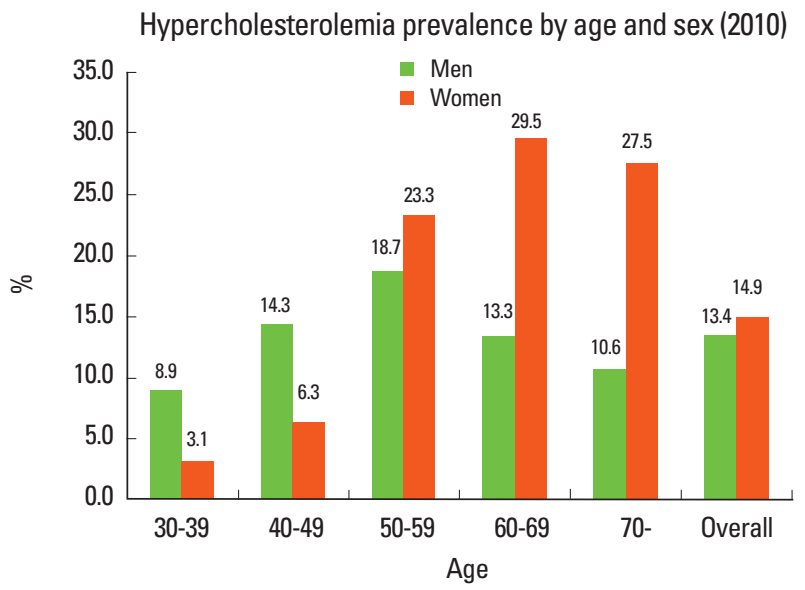

Figure 43. Hypercholesterolemia prevalence by age and sex (2010). Source: KNHANES 2010 
more prevalent in men than in women for all age groups (35.8\% vs. $17.4 \%$ ) (Figure 44). The prevalence of hypertriglyceridemia $(\geq 200 \mathrm{mg} / \mathrm{dL}$ ) was higher in men than in women, and in all age groups except for people aged $\geq 70$ years, hypertriglyceridemia was more prevalent in men than in women (Figure 45). ${ }^{13}$

\section{Serum levels of total cholesterol, HDL-cholesterol, and triglyceride}

According to data from KNHANES 2010, total cholesterol level was highest in the 40-49 age group for men and 50-59 years for women. For people 19-49 years of age, total cholesterol level was higher in men than in women, but from age 50 it was higher in women than in men (Figure 46). HDL-cholesterol level was higher in women than in men for all age groups, and triglyceride level was higher in men than in women for all age groups except for the aged $\geq 70$ years (Figure 47 ).

\section{Awareness, treatment, and control of hypercholesterolemia}

Data from KNHANES 2008-2010 showed that among peo-

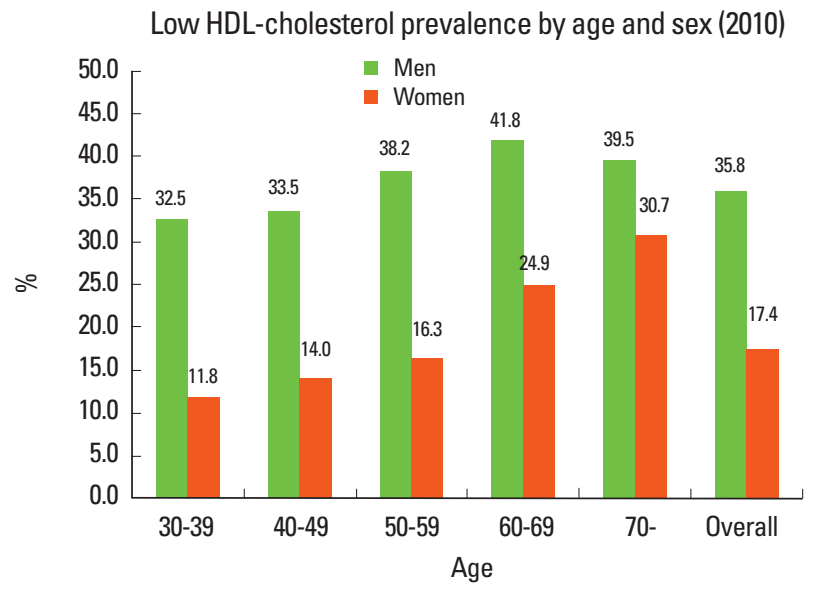

Figure 44. Low HDL-cholesterol prevalence by age and sex (2010).Source: KNHANES 2010.

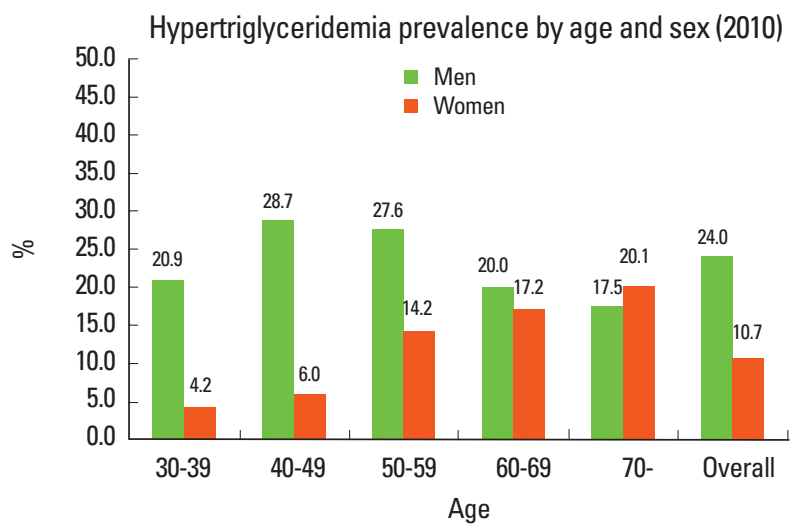

Figure 45. Hypertriglyceridemia prevalence by age and sex (2010). Source: KNHANES 2010. ple aged $\geq 30$ years with hypercholesterolemia, $45.4 \%$ were aware of their hypercholesterolemia (diagnosed by physicians), $34.7 \%$ were on regular treatment (taking medication $\geq 20$ days per month), and $25.9 \%$ had their cholesterol level under control (total cholesterol level $<200 \mathrm{mg} / \mathrm{dL}$ ). ${ }^{13}$ The awareness, treatment, and control of hypercholesterolemia improved compared to data of KNHANES 2007-2009, and the magnitudes of improvement were greater in women than in men(Figure 48). ${ }^{34}$

Overall, women had higher percentages of awareness, treatment, and control of hypercholesterolemia than men. Younger age groups had lower percentages of awareness, treatment, and control of hypercholesterolemia than elderly groups. Among people 30-39 years of age, $<20 \%$ were aware of their hypercholesterolemia, $<10 \%$ had regular treatment, and $<3 \%$ had their cholesterol level under control (Figure 49).

\section{Atrial fibrillation}

There has been no representative population-based study for incidence and prevalence of atrial fibrillation in Korea. Howev-

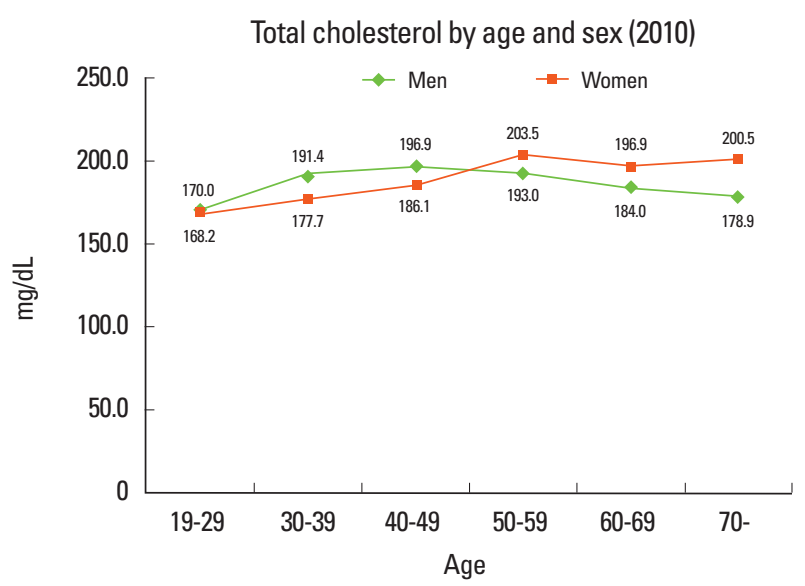

Figure 46. Source: Total cholesterol by age and sex (2010). KNHANES 2010.

HDL-cholesterol and triglyceride by age and sex (2010)

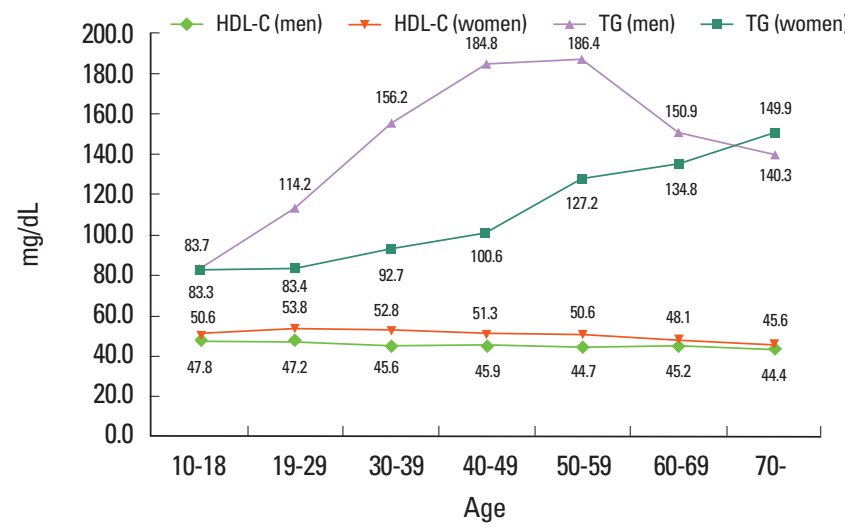

Figure 47. HDL-cholesterol and triglyceride by age and sex (2010). Source: KNHANES 2010. 
Trends of awareness, treatment, and control of hypercholesterolemia

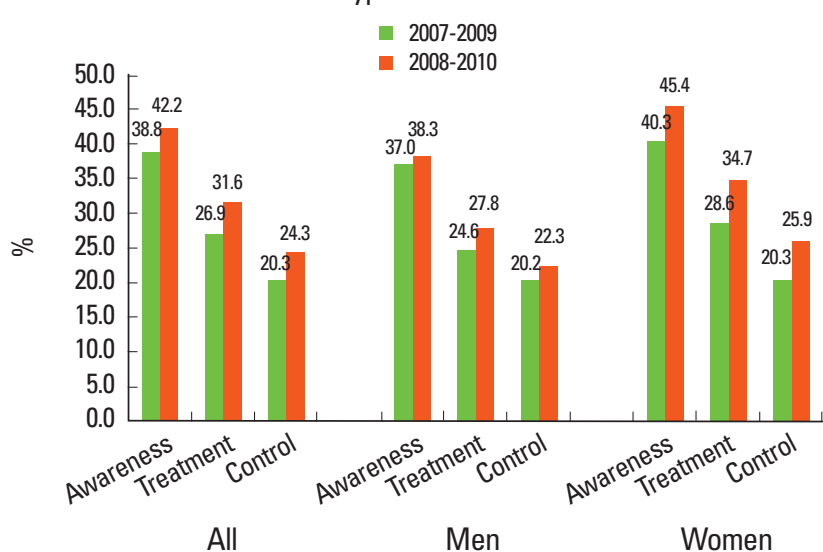

Figure 48. Trends of awareness, treatment, and control of hypercholesterolemia. Source: KNHANES 2010.

er, one study reported the prevalence of atrial fibrillation in 14,540 adults $(6,573$ men and 7967 women who were $\geq 40$ year-old inhabitants in 5 cities and 3 counties in Gyeongsangnam-do) who underwent general health screening test including electrocardiography between April 2000 and December 2000. The prevalence of AF in people $\geq 40$ years of age was $0.7 \%$ ( $1.2 \%$ in men and $0.4 \%$ in women). The AF prevalence was higher in men than in women for all age groups and generally increased with aging: $40-49$ years of age, $0.1 \%(0.1 \%$ in men; $0.1 \%$ in women); $50-59$ years, $0.5 \%$ ( $0.7 \%$ in men; $0.4 \%$ in women); $60-69$ year, $1.4 \%$ (2.5\% in men; $0.5 \%$ in women); $70-79$ years, $1.8 \%$ ( $2.7 \%$ in men; $1.0 \%$ in women); and $\geq 80$ years, $4.0 \%$ (4.5\% in men; $3.5 \%$ in women)..$^{38}$ Accordingly, an estimated 138,000 Korean people $\geq 40$ years of age have atrial fibrillation (estimated from the 2005 standardized population). Since elderly population $\geq 65$ years of age is estimated to increase by 5.8 -fold in $2050,{ }^{5}$ the projected AF prevalence in 2050 would be more than 800,000 in Korea. The prevalence of $4.0 \%$ in Korean people aged $\geq 80$ years was substantially lower than that of $10 \%$ in US population of the same age. ${ }^{39}$ Since only $1.2 \%$ $(n=175)$ of all examined populations were $\geq 80$ years, ${ }^{38}$ a welldesigned study that includes more elderly patients is required.

\section{Obesity}

Obesity increases blood pressure, blood glucose, blood cholesterol, and the risk of stroke.

\section{Prevalence}

Obesity in this report is defined as body mass index (BMI) $\geq 25$.

One in 3 Korean adults aged $\geq 19$ years is obese, an estimated $8,800,000$ adults (data from 2010 KNHANES adjusted to 2005

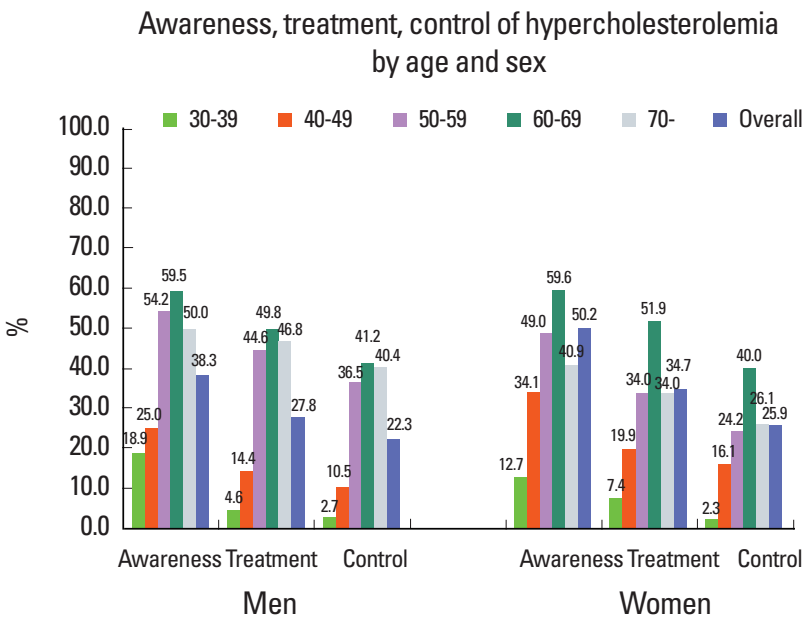

Figure 49. Awareness, treatment, control of hypercholesterolemia by age and sex. Source: KNHANES 2010.

standardized population). ${ }^{13}$ During the period of 1998-2010, the age-standardized prevalence of obesity substantially increased in men from $21.1 \%$ to $36.3 \%$, but slightly decreased in women from $26.2 \%$ to $24.8 \%$ (Figure 50 ). ${ }^{13}$

Data from KNHANES 2010 showed that $31.4 \%$ of population $\geq 19$ years of age were obese. Obesity was more prevalent in men than in women ( $36.5 \%$ vs. $26.4 \%$ ). Until 59 years of age, the prevalence of obesity was higher in men than in women, but from 60 years of age, obesity was more prevalent in women than in men (Figure 51). ${ }^{13}$ In those less than 40 years of age, the prevalence of obesity in men was more than twice than in women.

Data from KNHANES 2010 showed that the peak prevalence of obesity differed between men and women. For women, the prevalence increased until 60-69 years of age, and then decreased. For men, the prevalence was highest in 30-39 years of age, and then generally decreased after 40 years (Figure 51 ).

According to data from KNHANES 2010, similar to obesity prevalence, BMI increased until 60-69 years of age in women and then decreased. For men, the BMI was greatest in 30-39 years and then decreased after 40 years (Figure 52).

\section{Recommended physical activity}

In this report, the recommended physical activity indicates a vigorous intensity of physical activity for $\geq 10$ minutes at a time, $\geq 20$ minutes per day, and $\geq 3$ days per week, or a moderate intensity of physical activity or walk for $\geq 10$ minutes at a time, $\geq 30$ minutes per day, and $\geq 5$ days per week.

Data from KNHANES 2010 showed that only 50\% of population $\geq 19$ years of age engaged in the recommended physical activity. The proportion of population who met the recommendation generally decreased during the period of 2005-2010 from $68.5 \%$ to $50.8 \%$ (Figure 53). For all age groups except for $40-49$ 
Trends of age-standardized prevalence of obesity $(\mathrm{BMI} \geq 25)$

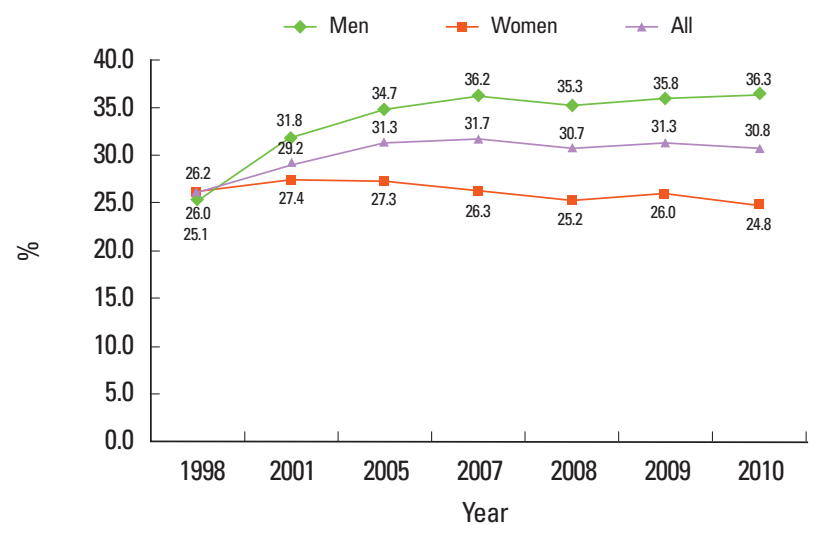

Figure 50. Trends of age-standardized prevalence of obesity (BMI $\geq 25)$. Source: KNHANES 2010.

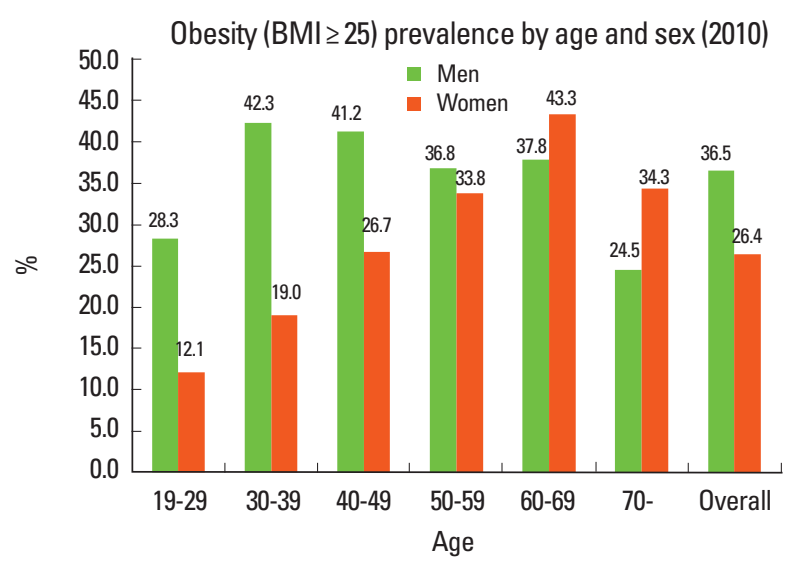

Figure 51. Obesity (BMl $\geq 25)$ prevalence by age and sex (2010). Source: KNHANES 2010.

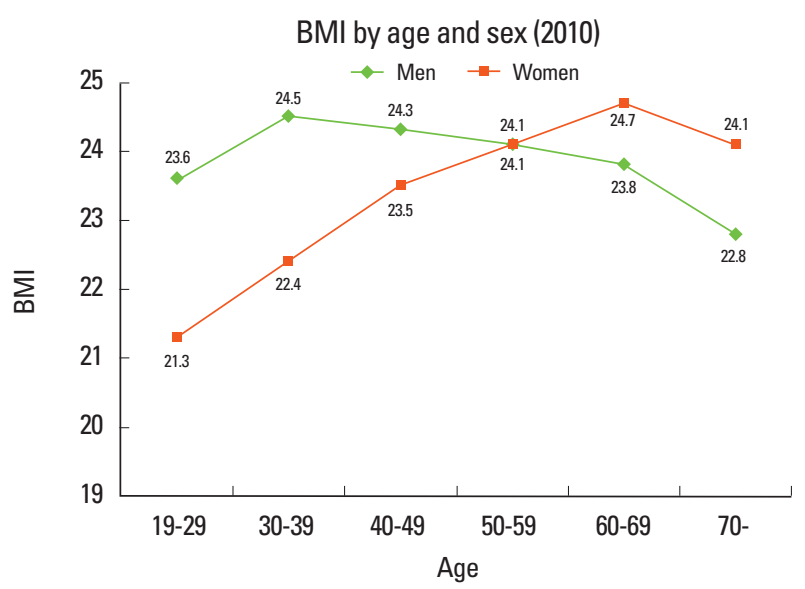

Figure 52. BMI by age and sex (2010). Source: KNHANES 2010.

years of age, the proportions of people who met the recommended physical activity were greater in men than in women. Among women $\geq 70$ year of age, less than $40 \%$ met the recommendation (Figure 54). ${ }^{13}$
Trends of age-standardized recommended physical

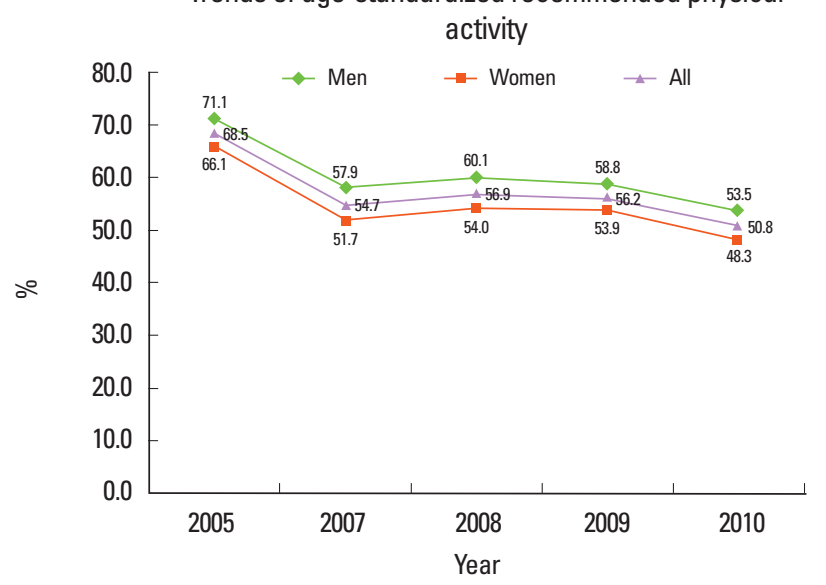

Figure 53. Trends of age-standardized recommended physical activity. Source: KNHANES 2010.

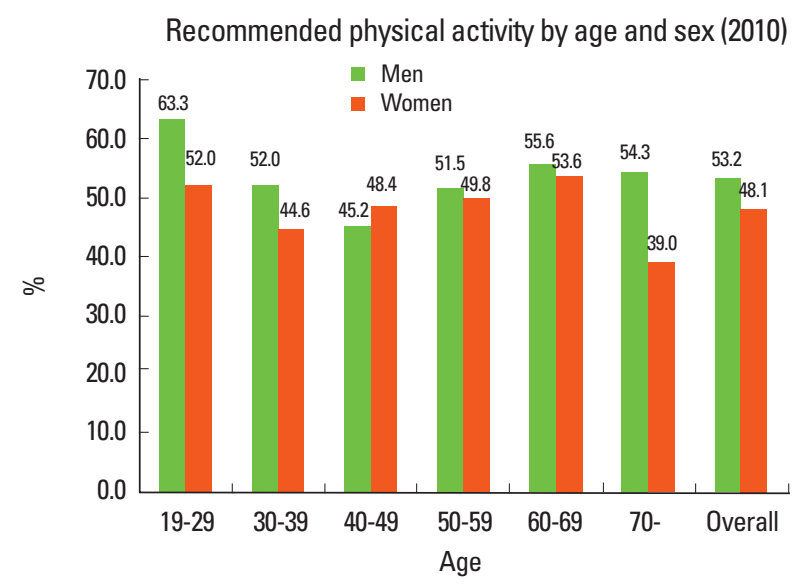

Figure 54. Recommended physical activity by age and sex (2010). Source: KNHANES 2010.

\section{Proportions of risk factors in patients with ischemic stroke or TIA in Korea}

According to a nation-wide hospital-based stroke registry enrolling 46,098 patients with ischemic stroke or TIA between 2002 and 2010, HT was the most common risk factor (63.5\%) followed by smoking (33.0\%), DM (30.1\%), prior stroke (19.7\%), potential sources of cardioembolism (19.4\%), and dyslipidemia $(19.3 \%){ }^{4}$

Over the nine years, the average age increased from 64.5 years to 66.7 years. The proportions of HT, DM, smoking, and prior stroke slightly but significantly decreased (for all, $\mathrm{p}$ for trends $<0.001$ ), whereas the proportion of potential source of cardioembolism did not change. Trend of dyslipidemia proportions showed a complex pattern of non-directional fluctuation between 2002-2007, a decline between 2007-2008, and then an increase since 2008 . 
Population attributable risk of major stroke risk factors in Korea

The relative risk (RR) is the risk of developing a disease associated with exposure to a risk factor. The RR indicates the strength of association between risk factor and disease, but it could not delineate the disease burden of the population due to the risk factor. Therefore, the population attributable risk (PAR) is usually employed for a population-based approach such as planning public health interventions. The PAR indicates the number (or proportion) of diseases (for example, strokes) that would be averted if a risk factor (for example, hypertension) is eliminated from a population. The PAR in a population depends on the prevalence of the risk factor and the strength of its association (relative risk) with the disease. For example, the RR of stroke is greater with atrial fibrillation than with smoking. However, since smoking prevalence is much greater than atrial fibrillation prevalence, the PAR of smoking is greater than that of atrial fibrillation.

To estimate the current PARs of individual risk factors in a population, contemporary population-specific prevalence and $\mathrm{RR}$ for each risk factor should be determined. In Korea, $\mathrm{KNH}$ ANES has regularly estimated the prevalence of major cardiovascular risk factors, but cohort studies estimating $R R$ of each risk factor for stroke have been very limited.

According to a prospective cohort study performed in 1990s and early 2000s, among major risk factors, hypertension had the highest PARs for stroke in men (35\%) and women (24.7\%), which were greater than those for ischemic heart disease $(21 \%$ for men and $16.2 \%$ for women). The PAR of smoking for stroke was high for men (26\%), but low (3.3\%) for women. Diabetes and hypercholesterolemia had relatively low PARs in men $(2.8 \%$ for diabetes and $2.6 \%$ for hypercholesterolemia). ${ }^{40,41}$

In another systematic review which employed prevalence

PAR for ischemic stroke by sex

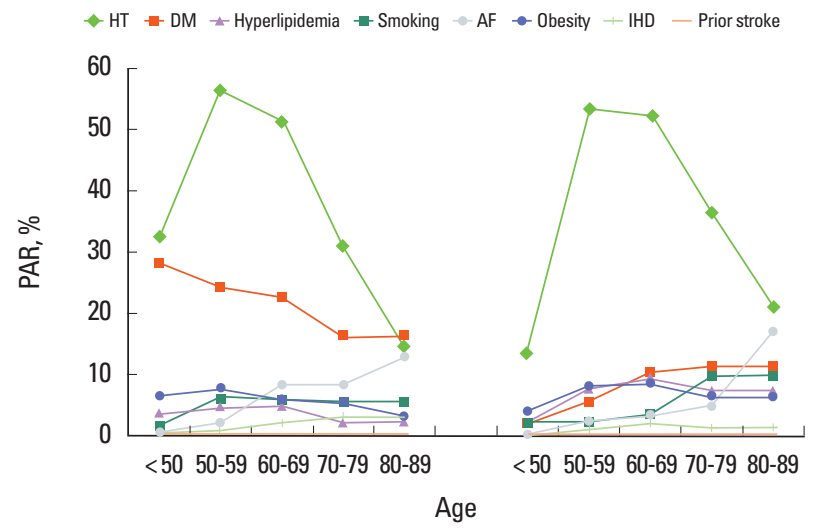

Figure 55. PAR for ischemic stroke by sex. Source: Park et al. ${ }^{42}$ with permission of the publisher. data of 2005 KNHANES and RR from data of Korean or other population, the PARs for ischemic stroke in men were 19.9$30.5 \%$ for hypertension, $26.5 \%$ for smoking, $6.6-23.5 \%$ for obesity, $2.8-7.2 \%$ for diabetes, $2.8-4.0 \%$ for hypercholesterolemia, and $3.5 \%$ for atrial fibrillation. In women, the PAR was 17.1$26.6 \%$ for hypertension, $4.1-7.2 \%$ for diabetes, $5.4 \%$ for obesity, $3.3-4.7 \%$ for hypercholesterolemia, 3.2\% for smoking, and $2.8 \%$ for atrial fibrillation. ${ }^{42}$ In the population 50-89 years of age, with increasing age, the PARs of hypertension decreased (from 56.2\% for men and $53.4 \%$ for women to $14.5 \%$ for men and $20.9 \%$ for women), whereas those of atrial fibrillation increased (from $2.2 \%$ for men and $2.3 \%$ for women to $12.8 \%$ for men and $17.0 \%$ for women) (Figure 55).

\section{Summary}

Stroke remains a great health burden in Korea. Risk factors for stroke are highly prevalent. Awareness, treatment, and control of risk factors have generally improved, but still have much room for improvement. Characteristics of stroke and risk factors are changing and healthcare providers need to cope with the changes. The current report of Stroke Statistics in Korea could be a valuable resource for clinicians, researchers, healthcare policy makers, and lay public who seek the best national data on stroke to establish a healthcare plan and to guide future research directions. The writing group will continuously monitor and evaluate data on stroke to update the Stroke Statistics in Korea.

\section{References}

1. Organization for Economic Cooperation and Development. OECD Economic Surveys: Korea 2010. OECD Web site http: //www.oecd.org/dataoecd/14/34/45432048.pdf. Accessed April 2011.

2. Asplund K, Eriksson M, Persson O. Country comparisons of human stroke research since 2001. Stroke 2012;43:830-837.

3. Korean Center for Disease Control. Construction of national surveillance system for cardiovascular \& cerebrovascular diseases. 2006.

4. Jung KH, Lee SH, Kim BJ, Yu KH, Hong KS, Lee BC, et al. Secular trends in ischemic stroke characteristics in a rapidly developed country: results from the Korean Stroke Registry Study (secular trends in Korean stroke). Circ Cardiovasc Qual Outcomes 2012;5:327-334.

5. Korean Statistical Information Service (KOSIS). Population projections and summary indicator for Korea (Population items). http://kosis.kr/eng/database/database_001000.jsp?li 
stid=A\&subtitle=Population/Household. Accessed July 18, 2012.

6. Korean Center for Disease Control. Development of strategy and action plans for major chronic diseases prevention and control. 2004.

7. Korean Health Insurance Review \& Assessment Service. Report of assessment for quality of acute stroke care in Korea, 2005.

8. Korean Health Insurance Review \& Assessment Service. Report of assessment for quality of acute stroke care in Korea, 2008.

9. Korean Health Insurance Review \& Assessment Service. Report of assessment for quality of acute stroke care in Korea, 2010.

10. Han DH, Kang HS, Kim GK, Oh CW. Current status of stroke management in Korea. Jpn J Stroke 2002;24:295-304.

11. Adams HP, Jr., Bendixen BH, Kappelle LJ, Biller J, Love BB, Gordon DL, et al. Classification of subtype of acute ischemic stroke. Definitions for use in a multicenter clinical trial. TOAST. Trial of Org 10172 in Acute Stroke Treatment. Stroke 1993; 24:35-41.

12. Ministry of Health \& Welfare, Korea Center For Disease Control \& Prevention. Korea Health Statistics 2005: Korea National Health and Nutrition Examination Survey (KNHANES III).

13. Ministry of Health \& Welfare, Korea Center For Disease Control \& Prevention. Korea Health Statistics 2010: Korea National Health and Nutrition Examination Survey (KNHANES V).

14. Korean Statistical Information Service (KOSIS). Annual Report on the Cause of Death Statistics 2010.

15. Korean Statistical Information Service (KOSIS). Annual Report on the Cause of Death Statistics. http://kostat.go.kr/portal/korea/kor_nw/2/6/2/index.board. Accessed July 18, 2012.

16. Korean Center for Disease Control. Health Behavior and Chronic Disease Statistics 2005.

17. OECD (2011), Health at a Glance 2011: OECD Indicators, OECD Publishing. http://dx.doi.org/10.1787/health_glance2011-en.

18. Duncan PW, Goldstein LB, Matchar D, Divine GW, Feussner J. Measurement of motor recovery after stroke. Outcome assessment and sample size requirements. Stroke 1992;23:10841089.

19. Lees KR, Bath PMW, Schellinger PD, Kerr DM, Fulton R, Hacke W, et al. Contemporary Outcome Measures in Acute Stroke Research. Stroke 2012;43:1163-1170.

20. Kasner SE. Clinical interpretation and use of stroke scales. Lancet Neurol 2006;5:603-612.

21. Hong KS, Kang DW, Koo JS, Yu KH, Han MK, Cho YJ, et al. Impact of neurological and medical complications on 3-month outcomes in acute ischaemic stroke. European Journal of Neurology 2008;15:1324-1331.

22. Kim J, Song TJ, Park JH, Lee HS, Nam CM, Nam HS, et al. Different prognostic value of white blood cell subtypes in patients with acute cerebral infarction. Atherosclerosis 2012;222: 464-467.

23. Ko Y, Han MK, Kim WJ, Kwon OK, Oh CW, Jung C, et al. Differences of mortality and dependence between stroke unit and general ward care in acute ischemic stroke patients. J Korean Neurol Assoc 2009;27:116-122.

24. Kim KH. Predictors of 30-day mortality and 90-day functional recovery after primary intracerebral hemorrhage: hospital based multivariate analysis in 585 patients. J Korean Neurosurg Soc 2009;45:341-349.

25. Murray CJ. Rethinking DALYs. In: Murray CJ, Lopez AD. The Global Burden of Disease. Cambridge, MA: Harvard University Press. 1996;1-98.

26. Kim AS, Johnston SC. Global variation in the relative burden of stroke and ischemic heart disease. Circulation 2011;124:314323.

27. Johnston SC, Mendis S, Mathers CD. Global variation in stroke burden and mortality: estimates from monitoring, surveillance, and modelling. Lancet Neurol 2009;8:345-354.

28. Hong KS, Kim J, Cho YJ, Seo SY, Hwang SI, Kim SC, et al. Burden of ischemic stroke in Korea: analysis of disability-adjusted life years lost. J Clin Neurol 2011;7:77-84.

29. Lim SJ, Kim HJ, Nam CM, Chang HS, Jang YH, Kim S, et al. Socioeconomic costs of stroke in Korea: estimated from the Korea national health insurance claims database. J Prev Med Public Health 2009; 42:251-260.

30. Kang HY, Lim SJ, Suh HS, Liew D. Estimating the lifetime economic burden of stroke according to the age of onset in South Korea: a cost of illness study. BMC Public Health 2011; 11:646.

31. Lewington S, Clarke R, Qizilbash N, Peto R, Collins R. Agespecific relevance of usual blood pressure to vascular mortality: a meta-analysis of individual data for one million adults in 61 prospective studies. Lancet 2002;360:1903-1913.

32. Psaty BM, Lumley T, Furberg CD, Schellenbaum G, Pahor M, Alderman $\mathrm{MH}$, et al. Health outcomes associated with various antihypertensive therapies used as first-line agents: a network meta-analysis. JAMA 2003;289:2534-2544.

33. Kearney PM, Whelton M, Reynolds K, Muntner P, Whelton PK, He J. Global burden of hypertension: analysis of worldwide data. Lancet 2005;365:217-223.

34. Ministry of Health \& Welfare, Korea Center For Disease Control \& Prevention. Korea Health Statistics 2009: Korea National Health and Nutrition Examination Survey (KNHANES IV). 
35. Roger VL, Go AS, Lloyd-Jones DM, Benjamin EJ, Berry JD, Borden WB, et al. Heart disease and stroke statistics-2012 update: a report from the American Heart Association. Circulation 2012;125:e2-e220.

36. Stratton IM, Adler AI, Neil HA, Matthews DR, Manley SE, Cull CA, et al. Association of glycaemia with macrovascular and microvascular complications of type 2 diabetes (UKPDS 35): prospective observational study. BMJ 2000;321:405-412.

37. Amarenco P, Labreuche J. Lipid management in the prevention of stroke: review and updated meta-analysis of statins for stroke prevention. Lancet Neurol 2009;8:453-463.

38. Jeong JH. Prevalence of and risk factors for atrial fibrillation in Korean adults older than 40 years. J Korean Med Sci 2005;20: 26-30.

39. Go AS, Hylek EM, Phillips KA, Chang Y, Henault LE, Selby
JV, et al. Prevalence of diagnosed atrial fibrillation in adults: national implications for rhythm management and stroke prevention: the AnTicoagulation and Risk Factors in Atrial Fibrillation (ATRIA) Study. JAMA 2001;285:2370-2375.

40. Jee SH, Suh I, Kim IS, Appel LJ. Smoking and atherosclerotic cardiovascular disease in men with low levels of serum cholesterol: the Korea Medical Insurance Corporation Study. JAMA 1999;282:2149-2155.

41. Jee SH, Park J, Jo I, Lee J, Yun S, Yun JE, et al. Smoking and atherosclerotic cardiovascular disease in women with lower levels of serum cholesterol. Atherosclerosis 2007;190:306-312.

42. Park TH, Kim MK, Lee KB, Park JM, Lee SJ, Jung KH, et al. Population attributable risk of major risk factors for ischemic stroke in the Korean population. Korean J Stroke 2008;10:125133. 